\title{
Nepal's domestic material consumption-projection and causal impact of external financial inflows, services value-added, population, and economic growth
}

\author{
Bishal Baniya $^{1}$. Prem Prakash Aryal ${ }^{2}$
}

Received: 25 August 2021 / Accepted: 7 December 2021 / Published online: 14 January 2022

(c) The Author(s), under exclusive licence to Springer-Verlag GmbH Germany, part of Springer Nature 2021

\begin{abstract}
Literature on material flow accounting has increasingly emphasized the need for an equitable resource allocation for least developed countries (LDCs) considering their future growth and the social outcomes (e.g., poverty alleviation) they intend to deliver. This paper aims to project Nepal's domestic material consumption (DMC)—scale and structure for different economic growth scenarios. We also investigate the causal impact of exogenous factors: (1) external financial inflows, such as the remittance and official development assistance (ODA); (2) services value-added; (3) population; and (4) economic growth on DMC by material types (e.g. biomass, fossil fuels, non-metallic minerals, and metal ores). We use the R tools, ridge regression and its machine learning algorithms, the autoregressive-distributed lag approach, and the abovementioned variables' timeseries data between 1993 and 2017 as methodological and data tools. While Nepal's absolute DMC will increase even in the low-growth scenario, we found that the biomass-based DMC prevalent in many LDCs, including Nepal, will be non-metallic minerals-based — a material consumption trait of existing middle-income and emerging economies. Despite this, the United Nations' LDC graduation growth pathway, often assumed to deliver sustainable development objectives by policymakers in LDCs, including Nepal, is material intensive. The increase in the gross domestic product per capita, remittance, and $O D A$ cause a rise in DMC because of their strong correlation and causal relationship. In these circumstances, we suggest policy measures that can leverage present consumption-oriented remittances as a source of investment in up-scaling small-scale modern renewable energy technologies across the residential sector, particularly in rural areas. We suggest this policy measure considering the future rise in non-metallic minerals and the challenges to reduce it because of the rising urbanization.
\end{abstract}

Keywords Material consumption $\cdot$ Least developed country $\cdot$ Remittance $\cdot$ Official development assistance $\cdot$ Equitable resource allocation

\section{Introduction}

As in the rest of the World and the Asia-Pacific region, the Asian least developed countries (LDCs) such as Bangladesh, Cambodia, Laos, Myanmar, and Nepal have doubled their domestic material consumption (DMC) in the

Responsible Editor: Philippe Garrigues

Bishal Baniya

bishal.baniya@uts.edu.au

1 Institute for Sustainable Futures, University of Technology Sydney, Level 10, 235 Jones Street, Ultimo, Sydney, NSW 2007, Australia

2 Nepal Engineering College, Pokhara University, Pokhara, Nepal last two decades (WU Vienna 2020). Amidst the growing DMC in LDCs and the debate on just transition and equitable resource allocation (Duro et al. 2018; O'Neill et al. 2018; Watari et al. 2021), two facets of DMC in the LDCs will need further attention from policymakers and research scholars. First, biomass is the dominant material type in the total DMC in most LDCs, which is not the case for the rest of the World. Due to the higher share of biomass in the DMC and the total energy consumption, the share of renewable energy in the energy mix is usually higher (over $50 \%$ ) than the global average of 18\% (World Bank 2021). However, if we exclude the traditional use of biomass, renewable energy shares drop to less than $10 \%$ for countries like Bangladesh, Cambodia, and Nepal (IEA 2021). Thus, reflecting on the lack of access to modern renewable energy technologies (e.g. hydroelectricity, solar, wind, and 
bioenergy), coupled with the anticipated future economic growth of today's LDCs, whose middle-class population is expanding (Steckel et al. 2013), further increase in their absolute DMC is expected. Second, LDCs have a high population density and the nation's total population, meaning a high material consumption potential. Therefore, a further increase in DMC is possible even if the lifestyle remains low to moderate. While almost $14 \%$ of the world's population lives in all LDCs, the Asian LDCs' share is about 4\% (World Bank 2021). Baniya et al. (2021a) found that the population factor is strong enough to drive much of the DMC in Asian LDCs, such as Bangladesh and Nepal.

Most LDCs aim to reduce their material consumption (e.g. biomass and fossil fuels) via delivering commitments to our generation's two important multilateral agreementsthe Paris Climate Agreement and the environment-related sustainable development goals (SDGs) 7, 12, and 13. The SDG 7 relates to improving access to affordable and clean energy, the SDG 12 pertains to the responsible consumption and production of resources, and the SDG 13 emphasizes enhanced climate actions. These commitments, together with their aspiration to seek promotion from the LDC status of the United Nations (UNCDP 2021), have put them in a unique position to deliver multilateral agreements' goals while increasing their economic outputs. Bangladesh, Laos, and Nepal will officially graduate from the LDC category in 2026 (UNCDP 2021), and this requires achieving at least a threshold level of the gross national income (GNI) per capita (US\$ 1,230). This unique position of LDCs is challenging for them because achieving economic objectives might endanger sustainable development objectives (Steckel et al. 2013), including reductions in material consumption. While the Paris Climate Agreement and the SDGs do not state how the signatory countries deliver both in a compatible manner (Hubacek et al. 2017), SDSN (2014) had suggested sustainable economic growth that should allow all LDCs to graduate by 2030 . However, what level of economic growth in LDCs is sustainable is far from being understood, mainly reflecting the common trend of a relatively higher economic growth rate in most LDCs (World Bank 2021).

In the absence of a common understanding about the environmentally sustainable economic growth pathway for LDCs, we can assume it as achieving the environmentrelated SDGs 7, 12, and 13 by 2030 while continuing to improve their GNI per capita figures to seek promotion from the LDC status. Murshed (2020) empirical findings pertaining to the trade liberalization policies in low-income countries suggest an alignment with the renewable energy policies that can contribute to achieving the SDG 7. Achieving the SDG 7 via renewable energy transition in oil-importing South Asian countries (e.g. LDCs such as Bangladesh and Nepal) is important as they may be exposed to oil price shocks that can impact progress in the GNI per capita
(Murshed and Tanha 2021). Baniya and Giurco (2021) state that SDG 12 and LDC graduation can co-exist and complement each other, meaning the assumed notion of the environmentally sustainable growth pathway is possible for LDCs. However, environmental sustainability objectives should be integrated into economic growth strategies, which will also help achieve SDG 13 (Murshed et al. 2021). This is relevant for South Asian nations with two LDCs, Nepal and Bangladesh.

In an intuitive sense, the most important aim for LDCs is poverty alleviation, which has become more prominent after the economic fallout from COVID-19 (Valensisi 2020). Alfredsson et al. (2018) implicitly support the notion of poverty alleviation in LDCs by stating that reductions in consumption should not be indiscriminate and that the consumption of people living on a low income can increase. The LDCs will require higher DMC per capita to achieve their sustainability outcomes, while developed countries will have to consider the needs of the LDCs (Schandl et al. 2018). Therefore, in theory, if we assume LDCs go beyond sustainable economic growth to reduce widespread poverty, DMC will likely be unsustainable and increase rapidly to cater to the consumption need of the households jumping out of poverty. In LDCs, resource-based economic growth is needed to overcome poverty (Giljum et al. 2014; Baniya et al. 2021c). The lack of understanding about the sustainable growth pathway in LDCs and the entailing DMC motivates this research to investigate the future DMC, its structure, and its key economic determinants in Nepal's case.

We take Nepal as a case country for two main reasons. First, we found that the GDP factor for DMC is relatively stronger for Nepal than another LDC, Bangladesh, meaning a macroeconomic change in Nepal has a relatively higher bearing on its DMC (Baniya et al. 2021a). Second, Nepal's GNI per capita is the lowest among the three Asian LDCs recommended for the LDC graduation in 2021, meaning the official development assistance (ODA) — an external financial inflow-may continue uninterrupted even after the LDC graduation (Baniya et al. 2021b). To date, we lack models and future projections of DMC for LDCs. Baniya et al. (2021a) developed a DMC model with Nepal and Bangladesh by taking GDP and population as exogenous variables. This research explores the role of external financial inflows, such as remittance and $O D A$, in the future DMC, which will shed light on macroeconomic factors. We use DMC instead of other material consumption indicators because DMC is the most prominently used material flow accounting indicator. It is considered the biophysical equivalent of the GDP (Schandl and Eisenmenger 2006). We discuss the DMC and its relationship with macroeconomic factors in Nepal in the "Domestic material consumption in Nepal and other Asian least developed countries" section. 
This research's main objective is to study Nepal's material consumption potential up to 2050, the DMC composition by material types between 2020 and 2050, and exogenous factors driving Nepal's DMC. This research is a first-hand attempt to create material consumption models by material types for LDCs, which is explained in detail in the following sections. Thus, it contributes to the emerging research on LDCs' material consumption and the driving factors, particularly the role of external financial inflows. We structure the rest of the paper as follows. The "A brief review of the literature" section provides a literature review of material consumption models. The "Domestic material consumption in Nepal and other Asian least developed countries" section presents a synopsis of material consumption in Nepal and other Asian LDCs. The "Methodology" section details the methodological approach. The "Results" section presents the findings. Finally, the "Discussion and conclusion" section discusses the findings and presents the conclusion.

\section{A brief review of the literature}

While we lack LDC-specific DMC models, there is a welldeveloped literature on material flow accounts and their projections across global, regional, national (non-LDCs), and urban scales. Krausmann et al. (2009) had discussed the growth in global material use resulting from the GDP and population in the twentieth century. Schandl and Eisenmenger (2006) investigated a regional resource extraction pattern related to resource extraction of different country groups based on income levels and geographical location with the GDP. Weisz et al. (2006) investigated the economywide material use in the EU-15 member state by considering population density as a driver to material consumption. Later research on material consumption, such as a study by Dong et al. (2017), focuses on China, South Korea, and Japan to discuss DMC resulting from changes in GDP, population, and technology (resource productivity ${ }^{1}$ ). Similarly, Schandl et al. (2018) analyze forty years of evidence on global material use and resource productivity to discuss growing wealth and consumption as drivers. The latter studies used the IPAT accounting model devised by Ehrlich and Holdren (1971) to discuss the role of technology. Alfredsson et al. (2018) emphasize the important role of technology (improvement in material intensity) in transforming the current unsustainable level of consumption and production. Thus, drawing on the research by Weisz et al. (2006), Krausmann et al. (2009), Schandl and Eisenmenger (2006), Dong et al. (2017), and Schandl et al. (2018), we infer that in the 2000s, the focus

\footnotetext{
${ }_{1}$ Resource productivity is commonly expressed as the unit value added in terms of the gross domestic product per unit of resource use.
}

was mainly on GDP and population as exogenous factors to material consumption. In contrast, in the 2010s, they added technology alongside GDP and population. However, other factors, such as latitude and climate data (Steinberger et al. 2010; Baynes and Musango 2018), renewable energy utilization (Alola et al. 2021), and sectoral value-added in GDP (Wu et al. 2019), are also used. This research presents a first-order attempt to explore the role of external financial inflows, such as remittance and $O D A$, as drivers to DMC in LDCs because of their notable contribution to the GDP of LDCs. Previous studies (Combes and Ebeke 2011; Haider et al. 2016; Dhakal and Oli 2020) have found that external financial inflows can influence the consumption behavior of individuals and households in the LDCs.

A study by $\mathrm{Wu}$ et al. (2019) found that the biomassdominated DMC of LDCs reacts less to the changes in the GDP. However, for two Asian LDCs, Nepal and Bangladesh, empirical research by Baniya et al. (2021a) found that the change in GDP, even under the low economic growth scenario, can significantly swing the future DMC. This contradiction shows the need to have LDC-specific studies on DMC, as Wu et al. (2019) used panel data models for 157 economies, and the purpose was to compare different country groups based on income level. Nonetheless, a comparison of countries provides valuable insights into equitable resource allocation. For example, Watari et al. (2021) use the contraction and convergence approach to show that LDCs may endeavor to increase their per capita material (metals) use, given their low material use per capita. O'Neill et al. (2018) use the planetary boundary approach to suggest that reducing material use in wealthy nations is possible without compromising social outcomes. If O'Neill et al. (2018) theoretical finding can be realized, LDCs can use additional material consumption to strengthen their social outcomes. Duro et al. (2018) analyzed the metabolic inequality among countries of different income levels and geographical locations to find that LDCs, together with the middle-income countries, increased their material intensity and material use between 2000 and 2010 because the affluence grew faster than material efficiency. These findings show a potential increase in material consumption in LDCs, as research scholars focus on reducing material consumption in wealthy nations and equitable resource allocation. However, there seems to be an assumption that equitable allocation of material use in LDCs will help achieve their social outcomes and sustainability goals. We discuss this assumption in the context of our findings in the "Discussion and conclusion" section.

While this research focuses on the implication of economic growth and external financial flows on material consumption, previous studies investigated the role of industrialization and economic progress, energy consumption and intensity, natural resource depletion, and financial 
Fig. 1 Domestic material consumption trend in Nepal by material types between 1985 and 2017 (Source: WU Vienna (2020))

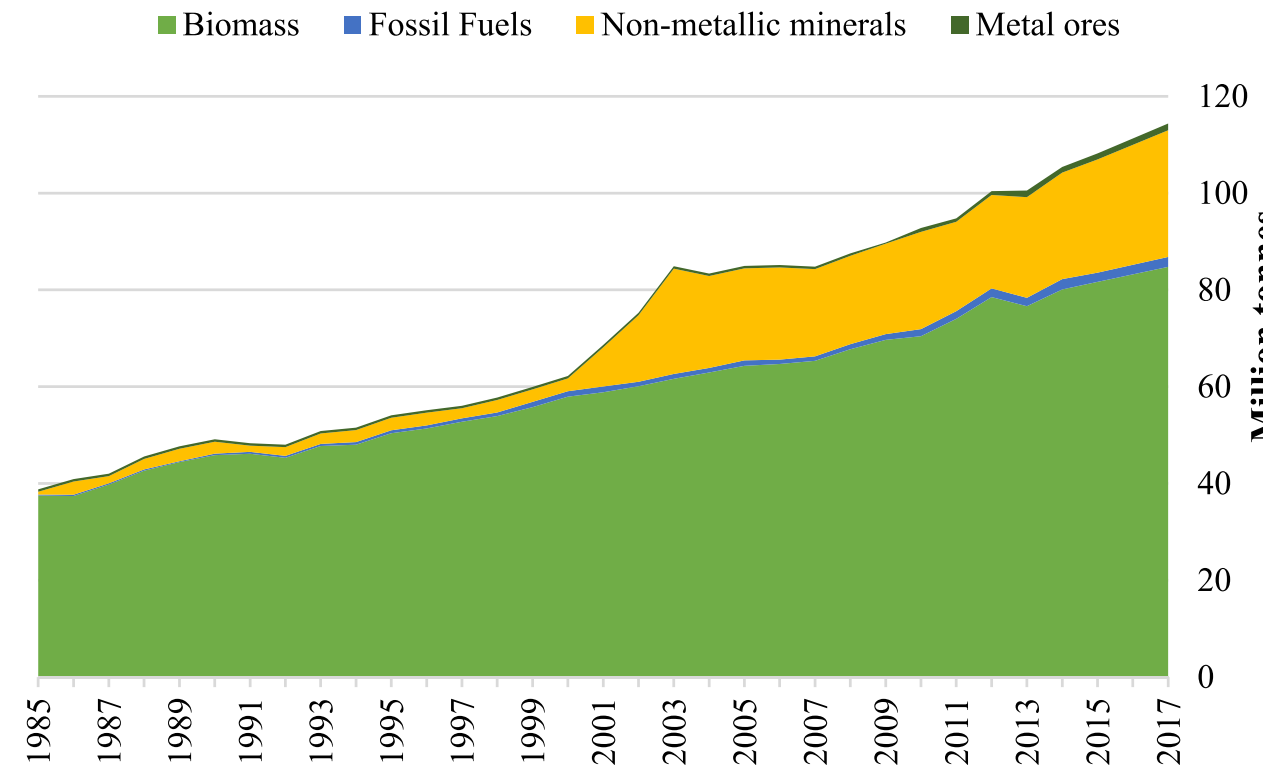

development (Khan et al. 2021; Rehman et al. 2021a, 2021b). These studies used time-series data analysis, causality analysis, and autoregressive-distributed lag models to explain the relationship between variables, generating a methodological contribution pertinent to research focusing on the environment-sustainability-development-energy nexus. This research builds on this methodological contribution to extending the aforementioned methodologies for material consumption-specific research targeting the LDCs. Furthermore, Ahmad et al. (2021) focus on the interaction of trade balance and exchange rate with economic and environmental indicators. Similarly, the recent literature focuses on variables such as globalization, trade, population growth, foreign investment, innovations, primary products (forestry, livestock, and crops), and fiscal policies to study the resource consumption-environmental sustainabilitydevelopment nexus (Rehman et al. 2021a, b, c, d, e; Hussain and Rehman 2021; Rehman et al. 2021d, 2021e; Weimin et al. 2021; Chishti et al. 2021). This research uses a similar approach to focus on material consumption-economic growth-environmental sustainability nexus.

\section{Domestic material consumption in Nepal and other Asian least developed countries}

The frequently cited material flow indicators database (WU Vienna 2020) divides domestic material consumption (DMC) into four types: biomass, fossil fuels, non-metallic minerals, and metal ores. This category is commonly used by research papers that focus on material flow accounting on various scales (Krausmann et al. 2009; Schandl et al. 2018; Schaffartzik and Pichler 2017; Wu et al. 2019). Thus, we use this category to show Nepal's DMC by material types between 1985 and 2017 (Fig. 1). Biomass has been the dominant material type in Nepal for 32 years. However, its share is in decline, mainly because of the rapid increase in the share of non-metallic minerals after 2000. Between 1985 and 2017, the share of biomass in the DMC decreased from 97 to $74 \%$. During the same period, the share of nonmetallic minerals increased from less than 2 to $23 \%$. The increased share of non-metallic minerals can be attributed to the increased GDP per capita by fourfold in just the last two decades (World Bank 2021). In addition, the consumption of construction commodities (e.g. cement, sands, and gravel) rose significantly to cater to the need for improved lifestyle and rapid urbanization even in semi-urban areas. While the share of metal ores appears constant, fossil fuels' share rose from less than $1 \%$ to about $2 \%$ between 1985 and 2017. However, in absolute terms, fossil fuels increased by almost 11-fold between 1985 and 2017 despite only about a threefold increase in the total DMC, biomass, and metal ores. Non-metallic minerals increased by nearly forty-five times between 1985 and 2017.

Figure 2 shows the absolute and per capita DMC of five LDCs by material types in 2015. Biomass is the dominant material type for all Asian LICs except Laos, whose per capita DMC is the highest. For others, the per capita DMC ranges between 2.5 to 5 tonnes, significantly lower than the world average of marginally less than 8 tonnes. However, one interesting aspect of the DMC per capita is that the biomass consumption per capita for all LDCs (1.3 to 2.2 tonnes) is close to the world's average ( 2.5 tonnes). The developed countries and emerging economies appear to have better access and better utilization of other material types (fossil fuels, non-metallic minerals, and metal ores). The almost non-existent per capita share of three material types (fossil fuels, non-metallic minerals, and metal ores) in the per 
Fig. 2 Absolute and per capita domestic material consumption of five Asian low-income countries by material types in 2015 (Source: WU Vienna (2020))

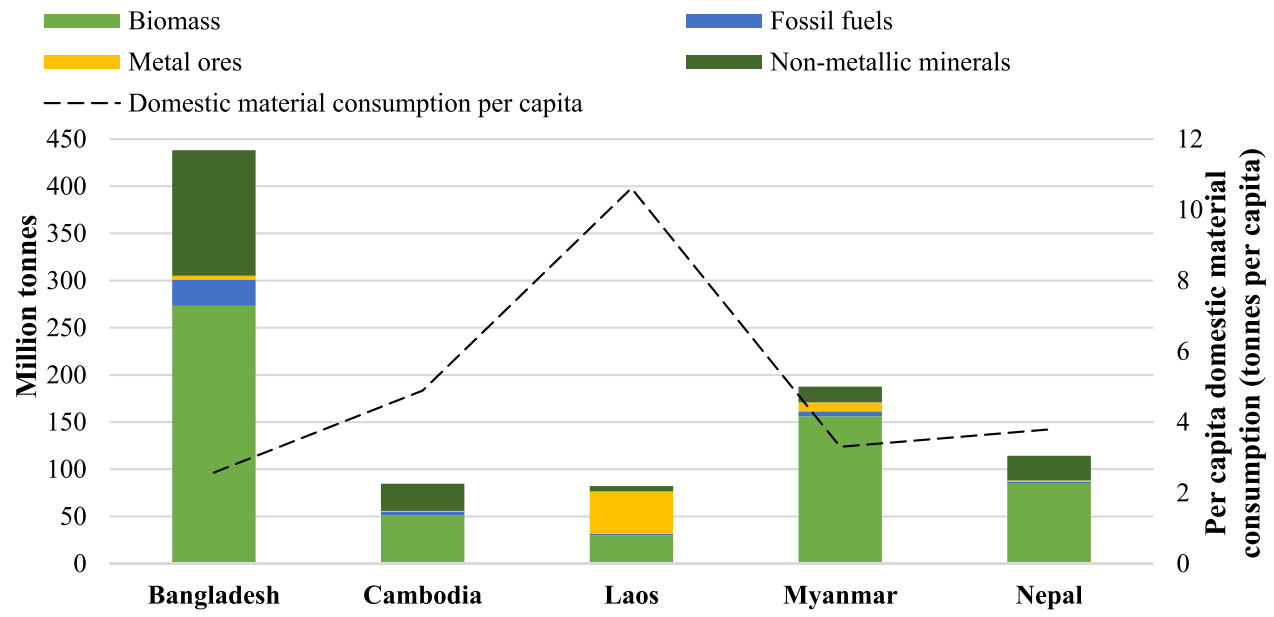

type, scenarios account for any changes in the future values of explanatory variables: remittance, $O D A, G D P C$, rural and urban population, and the share of the service sector in the total GDP. Third, we created autoregressive-distributed lag (ARDL) models and conducted Granger causality testing (Granger 1969) to characterize the dependence relationships between response variables-biomass, fossil fuels, non-metallic materials, and metal ores-and hypothesized explanatory variables' time series data. By this stage, our hypothesis is tested for validation by multiple tests, including model's assessment by multicollinearity checking, cross-validation, correlation analysis, diagnostic check of variables' time series data, unit root and cointegration tests, Granger causality test, and finally, the cumulative test for parameter stability. We also conduct impulse response analysis to study the impact of any shocks on explanatory variables to response variables. The following paragraphs explain the methodological approach.

\section{Regularized regression models and scenarios}

\section{Ridge regression}

We chose regularized regression method for three main reasons. First, the regularized regression method penalizes large coefficients of explanatory variables, usually found in linear regression models, to avoid over-fitting the models. Second, a regularized regression model can minimize the standard errors resulting from the multicollinearity between explanatory variables. Multicollinearity can also deflate the partial $t$ tests of coefficients' estimates, which result in the downgrading of the models' predictability. Third, we can achieve a balance between low bias and low variance by using regularized regression methods, meaning the coefficient estimates obtained from regularized regression methods avoid significant swings in their values with 
minor changes in explanatory variables' data. Regularized ridge regression method, introduced by Hoerl and Kennard (1970), adds a regularization parameter in the model to impose a penalty for shrinking the value of relatively less significant variables' coefficient estimates. The shrinkage penalty is denoted by " $\lambda$ " throughout this paper. We use ridge regression for two different purposes. First, the unstandardized coefficient estimates of explanatory variables alongside intercept values project the future material consumption by material types. Second, the standardized coefficient estimates help us understand the relationship between response and explanatory variables. In higher dimension models, when the explanatory variables are more than two, an alternative to the ridge regression, lasso regression
(Tibshirani 1996), can cause absolute shrinkage to some explanatory variables' coefficients that are relatively less significant in predicting the response variables' data. The remaining nonzeroed coefficient estimates are only the significant ones with a strong bearing on response variable values. Our selection of explanatory variables is based on our hypothesis, which is further tested in causality analysis. Therefore, it was unreasonable to cause absolute shrinkage to potentially insignificant variables. Hence, we chose ridge regression over lasso regression.

We construct ridge regression models for biomass $(B M S)$, fossil fuels $(F F)$, non-metallic minerals $(N M M)$, and metal ores $(M O)$ by using the following equations. We consider minimizing the impact of heteroscedasticity on the models, and therefore, we use a logarithmic scale for each variable.

$$
\log (B M C)=\alpha 0+\alpha 1 \log (G D P C)+\alpha 2 \log (\text { Rem })+\alpha 3 \log (O D A)+\alpha 4 \log (\text { Rurpop })+\mu
$$

$$
\log (F F)=\beta 0+\beta 1 \log (G D P C)+\beta 2 \log (\operatorname{Rem})+\beta 3 \log (O D A)+\beta 4 \log (\text { Urbpop })+\mu^{\prime}
$$

$\log (N M M)=\gamma 0+\gamma 1 \log (G D P C)+\gamma 2 \log ($ Rem $)+\gamma 3 \log (O D A)+\gamma 4 \log ($ Urbpop $)+\gamma 5 \log ($ ServicesShare $)+\mu^{\prime \prime}$

$$
\log (\mathrm{MO})=\delta 0+\delta 1 \log (G D P C)+\delta 2 \log (\mathrm{Rem})+\delta 3 \log (O D A)+\delta 4 \log (\text { Urbpop })+\delta 5 \log (\text { ServicesShare })+\mu^{\prime \prime \prime}
$$

where "GDPC" is the GDP per capita, "Rem" is the remittance received, "ODA" is the official development assistance received, "Rurpop" is the rural population, "Urbpop" is the urban population, and "ServicesShare" is the share of service value-added in the total GDP. The $\alpha_{0}, \beta_{0}, \lambda_{0}$, and $\delta_{0}$ are the constants, other $\alpha_{\mathrm{i}}, \beta_{\mathrm{i}}, \lambda_{\mathrm{i}}$, and $\delta_{\mathrm{i}}$ (for $i=1$ to 5) are the coefficient estimates, and the $\mu$ values are the error terms. We source the variables' time series data between 1993 and 2017 from the World Development Indicator Database (World Bank 2021) and the Material Flow Analysis Portal (WU Vienna 2020). The choice of exogenous drivers to material consumption by its type (Eq. (1) to Eq. (4)) is based on our hypothesis as the relationship between DMC and the growth in GDP is mainly explained by resource decoupling (Haberl et al. 2020). The relationship between DMC and external financial inflows is also less studied (Popescu et al. 2019). The traditional use of biomass for cooking in rural areas drives its consumption, and the urban transport system is mainly responsible for the use of fossil fuels in Nepal (Parajuli et al. 2014). The rapid rise of NMM (Fig. 1) corresponds to the significant rise in the share of service valueadded in the same period during the early 2000s in Nepal. Hence, their correlation and a causal relationship are tested.
We use the R tool (R core Team 2017) and its package "glmnet" (Friedman et al. 2010) to create ridge regression models in three steps. We identify the use of the regularized regression models, particularly the application of the ridge regression technique via $\mathrm{R}$ tools as the methodological contribution of this research as the method is rarely applied for material consumption models and the Granger causality analysis with LDC as a case study. The first step was to conduct the test for multicollinearity by using ordinary least regression and correlation analysis. Besides testing for multicollinearity, the correlation analysis visualizes variables' distribution, and bivariate scatter plots are generated. We use the "PerformanceAnalytics" (Peterson et al. 2015) statistical package for correlation analysis. The next step was to create training matrices and testing matrices by splitting the dataset as $60 \%$ and $40 \%$, respectively. The third step was to train and test models by using the "K-fold cross-validation method to enhance models" robustness. The K-fold cross-validation method is better than its alternative, such as the leave-one-out crossvalidation method, as the former provides more accurate estimates of the test error (Gareth et al. 2014). We use the "caret" package in $\mathrm{R}$ (Kuhn 2008) for K-fold cross-validation, creating $K=8$ models with eight different coefficient estimates and accuracy scores. For the value of $K$ between 5 and 10, the models do not suffer from high 
bias and high variance (Gareth et al. 2014). We chose the model with an optimal cross-validated sum of squared residuals.

\section{Primary and secondary scenarios for the projection of material consumption}

Projecting the future values of DMC by material types has uncertainty, mainly because of multiple explanatory variables and the potential fluctuations in their time-series data values. Therefore, we create scenarios to account for the uncertainty and project material consumption values in range instead of pinpointing their exact values. While we create six different scenarios, we divide them into two categories: primary scenarios and secondary scenarios. Primary scenarios consider the real values of explanatory variables from the past (based on empirical evidence). In contrast, secondary scenarios consider the nation's aspiration to achieve the LDC graduation status of the United Nations and meet their climate mitigation and SDGs commitments. Table 1 details their description. The primary scenarios are:

- Normal economic activity scenario (NEAS) assumes normal economic activities will resume and that the explanatory variables' trend, including the increase/decrease in rural and urban populations, will continue. We consider the trend in a decade between 2009 and 2019. This is also the reference scenario for other scenarios.

- Low economic activities scenario (LEAS), where the explanatory variables' GDPC, Rem, ODA, and ServicesShare take their lowest values, whereas the rural and urban population will continue its normal trend. The population-related explanatory variables continue their normal trend because we do not expect their yearly values to change significantly.

- High economic activities scenario (HEAS), where the explanatory variables' GDPC, Rem, ODA, and ServicesShare take their highest values, whereas the rural and urban population will continue its normal trend.

The secondary scenarios are:

- Least developed country graduation scenario (LDCGS), which considers the least developed country graduation of Nepal in 2026 and the gross national income per capita it will maintain beyond 2026. We estimate the LDC graduation level GDPC in 2026 by correlating it with the GNI per capita (see supplementary material).

- Climate mitigation scenario (CMS), which considers the delivery material consumption-related goals of the second nationally determined contributions of Nepal, submitted to the United Nations Framework Conventions for Climate Change (UNFCCC) in December 2020 (GoN 2020).
- Sustainable development goal scenario (SDGS), which considers the material consumption-related progress made against the SDGs (as reported by the Government of Nepal $(\mathrm{GoN})$ ) and the targets the GoN has set for 2030 (NPC 2020).

\section{Unit root test, cointegration, and causality testing}

\section{Unit root tests}

We use three unit root tests to determine the order of integration of variables' logarithmic data. First is the Augmented Dickey-Fuller (ADF) test (Dickey and Fuller 1979), the second is the Phillips Perron (PP) test (Phillips and Perron 1988), and the third is the Zivot-Andrews (ZA) test (Zivot and Andrews 2002). While the hypothesis testing procedure of the PP test and ADF test is similar, the PP test effectively deals with the autocorrelation and heteroscedasticity issues. We use the ZA test to consider the structural break in the variables' time-series data as other tests cannot reject the unit root hypothesis if there are structural breaks in the time-series data. We note both "constant" and "trend" types of statistics for ADF and PP tests. While the "constant" type adds intercept in the test regression, the "trend" type adds both intercept and trend. We use the critical values are provided by Hamilton (1994) and Dickey and Fuller (1981). For the ZA test, we note the "trend" model statistics as the potential structural break in the linear trend is of interest. We use the "urca" package (Pfaff 2016) in R tools to conduct ADF, PP, and ZA unit root tests.

\section{Cointegration test}

We use an autoregressive-distributed lag (ARDL) approach (Pesaran et al. 2001) to test cointegration between variables. ARDL approach is suitable when the variables have a mixed order of integration. In contrast, the alternatives of the ARDL approach, such as the EngleGranger and Johansen cointegration tests (Johansen 1991), require variables to be integrated of the same order. The unit root tests revealed that the explanatory variables (in Eq. (1) to Eq. (4)) are of $I$ (0) or $I(1)$. Furthermore, the ARDL method's performance in dealing with small sample sizes and an ability to estimate the short-run and the long-run relationship between variables makes it a preferred method to test for cointegration. In a general sense, the ARDL model can be expressed by the following equation (Eq. (5)).

$$
\begin{aligned}
Y_{t} & =\alpha+\sum_{i=1}^{k} \beta_{01} X_{t i}+\beta_{1 i} X_{(t-1) i}+\ldots \ldots \\
& +\beta_{p i} X_{(t-p) i}+\delta_{1} Y_{t-1} \ldots \ldots \ldots \ldots \ldots+\delta_{q} Y_{t-q}+e_{t}
\end{aligned}
$$

where $Y_{\mathrm{t}}$ is the response variable, $X_{\mathrm{ti}}$ is the $\mathrm{i}^{\text {th }}$ exploratory series, $k$ is the number of exploratory series, $p$ is the lag order, $q$ is the autoregressive order, and $e_{\mathrm{t}}$ is the error term.

We convert the Eq. (5) into a bound testing equation (Eq. (6)) that include both short and long-run dynamics. The bound testing equations generate cointegrating vectors that can be 


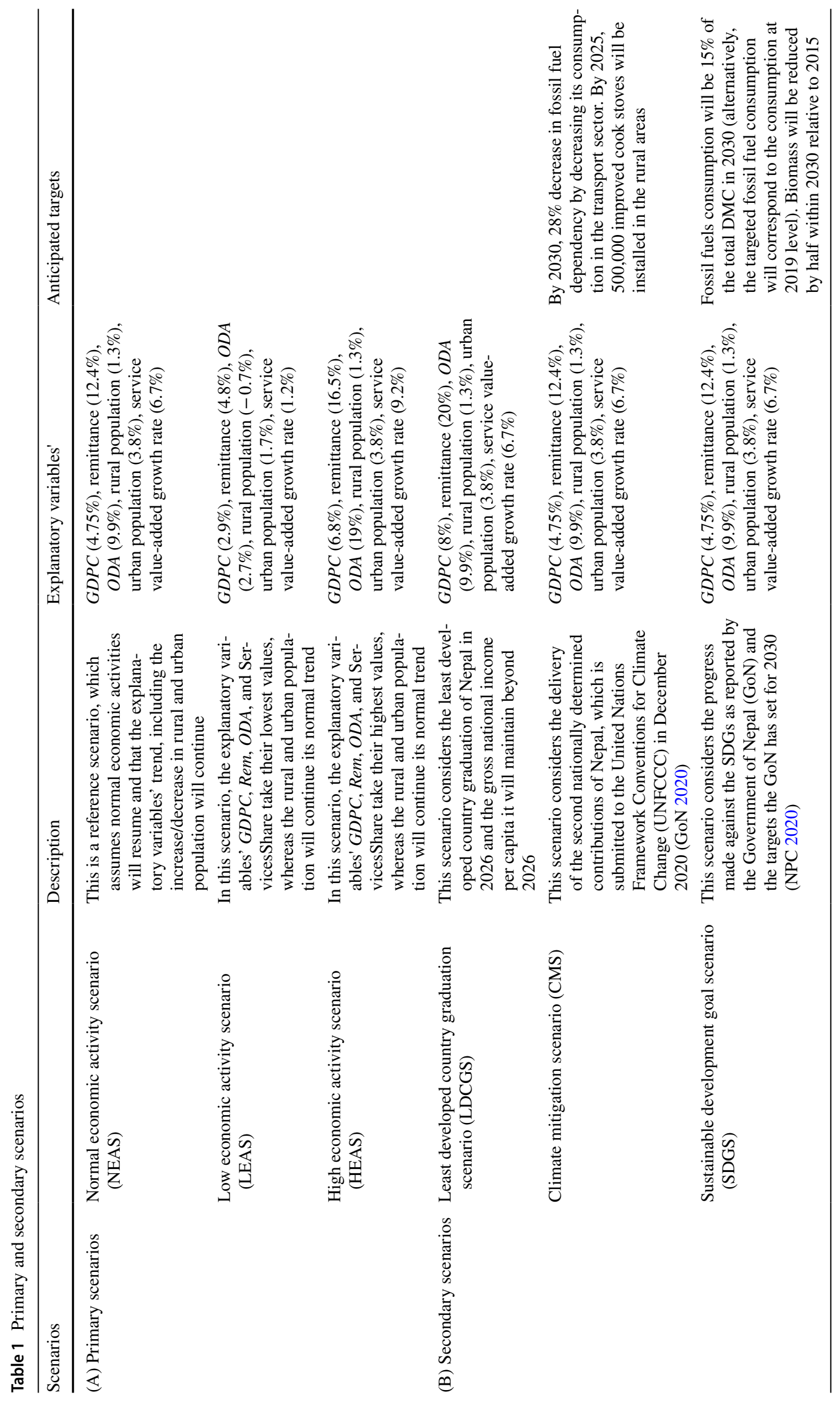


parameterized into error correction-based models. We conduct a bound $F$ test on ARDL bound testing equations where the maximum lag length of 3 is specified by using the " $\mathrm{dLgM}$ " package developed by (Demirhan 2020) in the R tools. Normally, in the ARDL bound test, the $F$ test value is compared with lower and upper bound critical values suggested by Pesaran et al. (2001). However, our sample size $(N=28)$ is small. Therefore, we check the $F$ test value with the lower and upper bound critical values suggested by Narayan (2004). If the $F$ test value from the bound test is higher than the upper bound critical value (5\% significance level), the null hypothesis of no cointegration is rejected. If the $F$ test value is lower than the lower bound critical ( $5 \%$ significance level), the null hypothesis is not rejected. If the $F$ test value lies between lower and upper bound critical values, the result is inconclusive. In this case, we reparametrize cointegrating vectors into error correction model (ECM) by rewriting Eq. (5) in the following error correction form.

$$
\begin{aligned}
& \Delta Y_{\mathrm{t}}=\alpha+\varphi_{0} Y_{\mathrm{t}-1}+\varphi_{1} X_{1, t-1}+\ldots \ldots \ldots \ldots . \\
& \Phi_{\mathrm{k}} X_{k, t-1}+\sum_{i=1}^{q} \delta_{\mathrm{i}} \Delta Y_{t-1}+\sum_{j=1}^{p 1} \beta_{1, j} \Delta X_{k, t-j} \\
& \quad+\ldots \ldots \sum_{j=0}^{p k} \beta_{\mathrm{k}, j} \Delta X_{k, t-j}+e_{t}
\end{aligned}
$$

where $\alpha$ is the intercept and $\Delta$ is the series' first difference. The error correction is expressed by Eq. (7).

$$
E C_{t-1}=Y_{t-1}-\sum_{i=1}^{k} \phi_{i} / \phi_{0} X_{\mathrm{i}, \mathrm{t}-1}
$$

\section{Causality testing}

While cointegration tests can identify cointegration between variables, they do not detect the direction of the causal relationship between variables. Therefore, as a usual way to test causality between variables in the presence of cointegration, we use a vector error correction model together with the Johansen cointegration test (Johansen 1991) that can identify both short-run and long-run causality and the direction of a causal relationship. In the absence of cointegration between variables, the vector autoregression model is usually the preferred one. The error correction-based causality test indicates long-run causality by including the lagged error correction term (ECT). While the $F$ statistics or a Wald test of differenced variables is used to test short-term causality, the $t$ test of the lagged error correction term is used to determine the long-run causality. We use $F$ statistics and $t$ statistics for causality testing. The equations (Eq. (8) and Eq. (9)) are the general form of the vector error correction model for causality testing.
$\Delta Y_{\mathrm{t}}=\alpha+\sum_{k=1}^{n} \beta_{1, k} \Delta Y_{\mathrm{t}-\mathrm{k}}+\sum_{k=1}^{n} \beta_{2, \mathrm{k}} \Delta X_{t-k}+\prod_{1} E C T_{t-1}+e_{1 t}$

$\Delta X_{t}=\alpha+\sum_{k=1}^{n} \beta_{1, k} \Delta X_{t-k}+\sum_{k=1}^{n} \beta_{2, k} \Delta Y_{t-k}+\prod_{2} E C T_{t-1}+e_{2 t}$

In the above equations (Eq. (8) and Eq. (9)), $E C T_{\mathrm{t}-1}$ denotes cointegration vectors, and the " $\Pi$ " values are adjustment coefficients that show the speed of adjustment toward an equilibrium path in a long-run cointegrating relationship. Thus, we identify a long-run causal relationship based on the adjustment coefficients, their significance level, and $t$ statistics values. For the short-run causal relationship, we note the coefficient of lagged terms of the explanatory variables, their significance level, and $F$ statistic values.

\section{Results}

\section{Multicollinearity test}

As shown in Fig. 3, we found multicollinearity between variables. The variables have high positive correlation values (over 0.80 ) in most cases, with statistically significant $p$ values $(p<0.01)$. The results from the diagnostic check-outputs from the OLS regression (see supplementary material 1) - further substantiated multicollinearity as the variance inflation factors (VIFs) are greater than 10 for all explanatory variables. The presence of multicollinearity validates the choice of the regularized regression method for creating material consumption models. The bivariate scatter plots (Fig. 3), variables' distribution, high positive correlation values, and significance levels show a strong relationship. The following sections elaborate on the relationship between variables.

\section{Results from the ridge regression}

Table 2 shows the unstandardized and standardized coefficients of the material consumption models, optimal shrinkage penalties $(\lambda)$, and optimal cross-validated sum of square residuals $\left(R^{2}\right)$. For the biomass (BMS) consumption model, the $G D P C$ appears to be the strongest factor, followed by the Rurpop, Rem, and the ODA. For the fossil fuels (FF) consumption model, the Urbpop is the strongest, followed by the GDPC. The Rem has a negative coefficient estimate, and the $O D A$ appears to have a minimum influence on $F F$ consumption. The non-metallic minerals (NMM) consumption model strongly affects a growing service sector's share in the GDP. The Rem, Urbpop, and the ODA follow ServicesShare in the NMM consumption model. The GDPC has a negative coefficient estimate, which signals that the NMM consumption will grow despite any economic downturn. Finally, the 

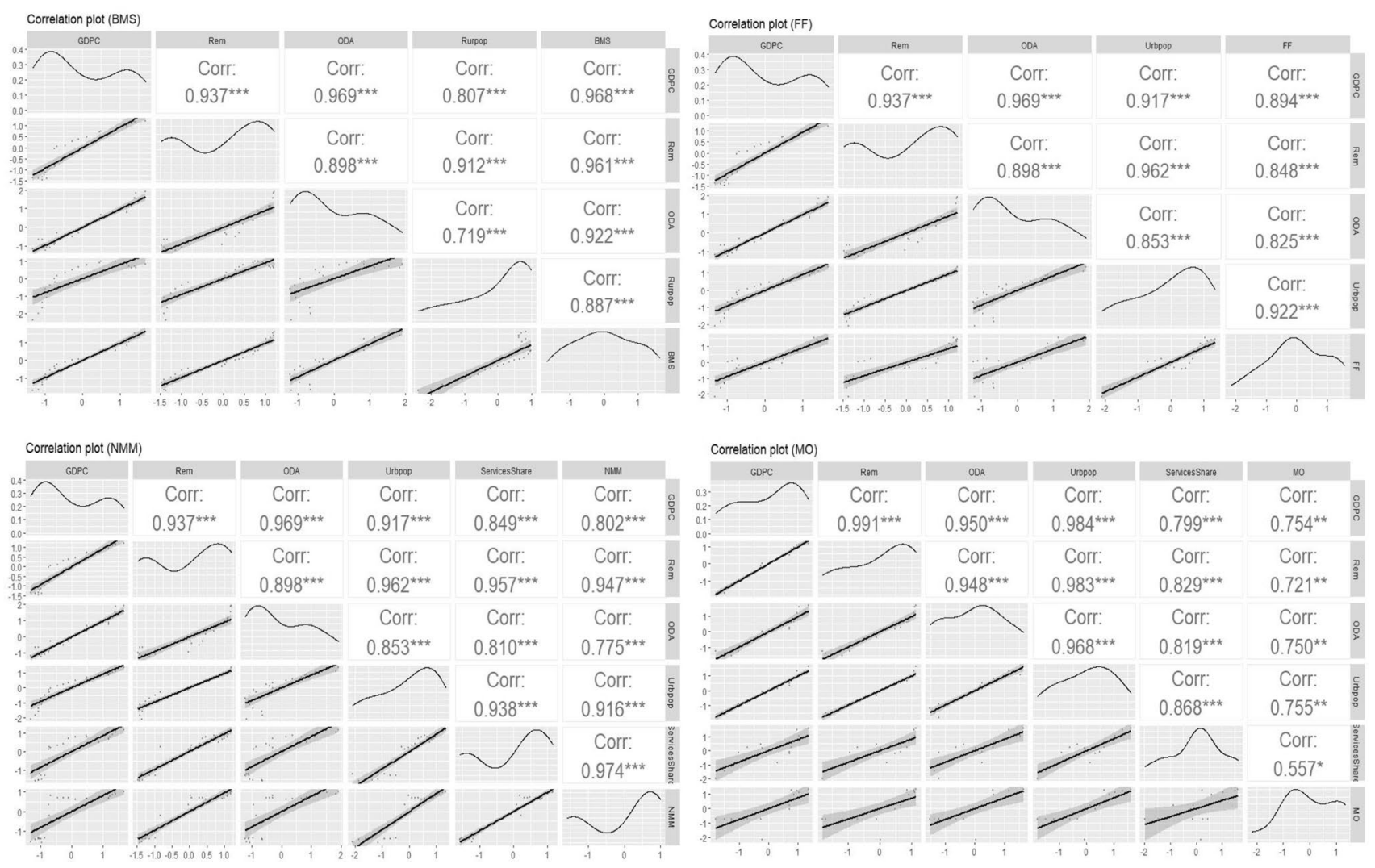

Fig. 3 Variables' distribution (diagonal), the bivariate scatter plots with fitted lines, and correlation values with significance levels (***significance at $1 \%, * *$ significance at $5 \%$, and $*$ at $10 \%)$

metal ore (MO) consumption model shows that the GDPC, Urbpop, Rem, and the $O D A$ are significant factors, whereas the service sector's share in the GDP is almost insignificant.

In an intuitive sense, the remittance inflow reduces the traditional use of biomass for cooking as the households with increased income have better access to clean fuels and technologies for cooking. However, we find that the remittance inflow is driving the $B M S$ consumption. Between 2000 and 2016, the percentage of the population with access to clean fuels and technologies for cooking increased from 15 to $25 \%$ in Nepal, and the access to electricity increased from $20 \%$ of the rural population to $90 \%$ in the same period (World Bank 2021). These figures indicate that most of the progress in the percentage of the population with access to clean fuels and technologies for cooking occurred in urban areas and that the major fraction of the rural population still prefers biomass as a cooking fuel over electricity. One reason for this is the fuel's price for cooking. While the electricity has some price, biomass from forests is almost freely accessible in most rural areas. The common biomasses in Nepal are logging residue, forest cleaning residues (pine needles and cones), timber industry residues (tree bark and sawdust), invasive plants and trees, and agriculture residues (Kafle et al. 2018). Another reason is the social factor (e.g., households' welfare and indigenous knowledge) pertaining to the traditional use of biomass for cooking in Nepal (Bharadwaj et al. 2021). Unlike the remittance, the $O D A$ inflows do not end up directly in the hands of biomass' enduse consumers. Nonetheless, based on its implicit relationship with biomass consumption, the $O D A$ and the government's investments are insufficient to incentivize modern clean energy technologies for cooking in rural areas. The government of Nepal used a significant proportion of the total $O D A$ received to improve the energy, industry, and construction sectors (OECD 2021). Most of the remittancereceiving households are in the rural areas (Wagle 2012), and therefore, it has a weak association with fossil fuel consumption, which is common in the urban areas, primarily in the transport sector of Nepal and for cooking in the urban areas (Parajuli et al. 2014; IEA 2021). Fossil fuels, such as liquified petroleum gas, have replaced a relatively low energy-intensity Kerosene in rural areas (Parajuli et al. 2014). Therefore, despite an absolute increase in fossil fuel consumption that followed a steady trend in the last two decades (Fig. 1), remittance appears to be a poor driver, particularly reflecting on its massive contribution to the GDP and because it ends up directly on end-use consumers' hand. The share of the remittance in the GDP jumped from 2.5\% 


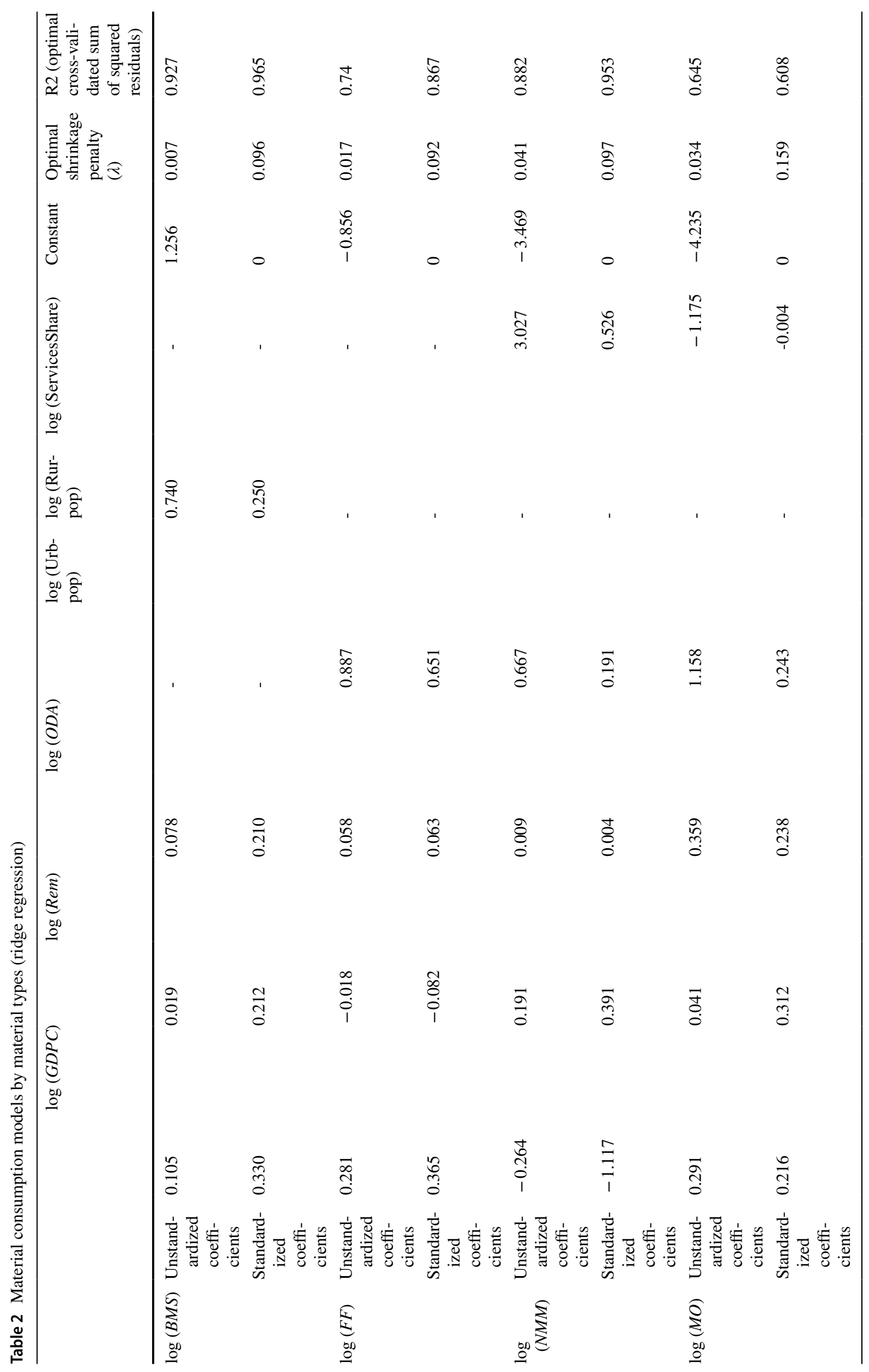



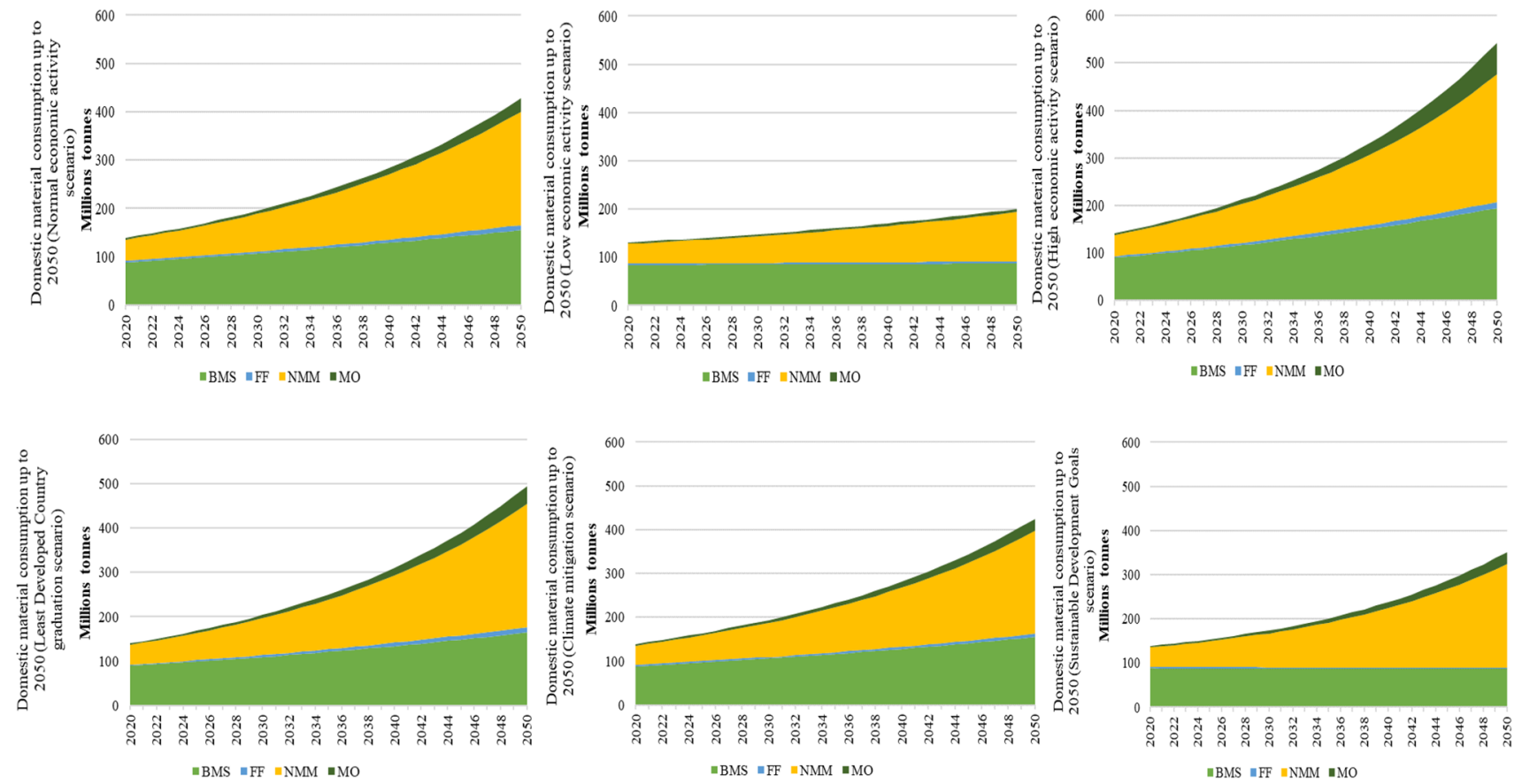

Fig. 4 Projected values of domestic material consumption by material types up to 2050 for the six scenarios

in 2001 to almost a quarter of the GDP in 2020 (World Bank 2021).

The negative coefficient of the GDPC (Table 2) in the $N M M$ consumption model is counterintuitive because an increase in income should drive consumption. Therefore, $G D P C$ is likely a confounding variable. The coefficients' shrinkage method, such as the regularized regression and the standardization of variables' data, can effectively deal with confounders (Kahlert et al. 2017). This research has employed both techniques, and we also undertake ARDL modelling and causality testing to explain better the relationship between the GDPC and NMM (in the "Unit test, cointegration, and causality analysis" section). The rapid rise in the share of the service sector in the GDP after 2000, and the increased urban population, together with the remittance, is driving the $N M M$ consumption. Nepal's service sector contributes to more than half of the nation's GDP (World Bank 2021), and it includes NMM consumption intensive sub-sectors such as the wholesale and retail trade; restaurants and hotels; transport, storage, and communications; and construction industry (UNCTAD 2011). These expanded a lot in the early 2000s via a rapid structural transformation that saw a significant shrinkage of Nepal's traditionally stronger agriculture sector (Dahal 2018). Most of the remittance-receiving rural households migrate to the urban areas, which is corroborated by the decreasing share of the rural population and the increasing share of Nepal's urban population (World Bank 2021). For the $M O$ consumption, remittance, $O D A, G D P C$, and urban population appear to be the drivers. However, the expansion of the service sector seems to have an insignificant effect on $M O$ consumption, mainly because of the incremental change in the quantity of $M O$ compared to that the $N M M$ (Fig. 2) that soared notably alongside the service sector and remittance share in the GDP during the early 2000 s.

\section{Material consumption forecast up to 2050}

Figure 4 shows the projected values of the DMC by material types up to 2050 for the six scenarios-normal economic activity scenario (NEAS), low economic activity scenario (LEAS), high economy activity scenario (HEAS), least developed country graduation scenario (LDCGS), climate mitigation scenario (CMS), and the sustainable development goal scenario (SDGS). In the HEAS, we project the DMC to be maximum, followed by the LDCG, NEAS, CMS, SDGS, and the LEAS. Figure 4 points to the five important findings. First, the absolute DMC will have about 1.5 times increase by 2050 (200 million tonnes) even in the LEAS and may increase up to five-fold by 2050 (530 million tonnes) relative to 2020 (140 million tonnes) if we consider all scenarios. This points to the importance of seeking ways to improve material use efficiency in Nepal and LDCs in general, as researchers often focus on middle- and high-income countries when it comes to reducing DMC via material efficiency. Many LDCs, including Nepal, are yet to utilize their full potential regarding DMC and that the current global material consumption is already unsustainable (WU Vienna 2020). 
Second, while the dominant material type in Nepal-biomass will increase steadily, the non-metallic minerals and metal ores will increase sharply, particularly after 2030 for all scenarios barring the LEAS. By the late-2030s, the nonmetallic minerals will be the dominant material type for all scenarios, comprising almost half of the total material consumption in all scenarios. In the LEAS, biomass use will remain almost constant, only to be caught up by the increasing use of non-metallic minerals. Biomass is consumed mostly in rural areas, meaning the low rural population growth rate in the LEAS will cause a slowdown of biomass consumption. Non-metallic minerals and metals are consumed mostly in the rapidly growing urban and semi-urban areas, and given the current and forecasted urban population growth rate, the two material types will form the majority of the future DMC at least until 2050.

Third, fossil fuel consumption will increase but contribute least to the total DMC between 2020 and 2050 for all scenarios. Except for the LEAS and the SDGs, biomass consumption will increase, meaning it might be the preferred fuel source, particularly in rural areas, compared to fossil fuels. In the SDGs, fossil fuels will decrease as the government targets to curb some of the increasing fossil fuel consumption, together with the biomass via a renewable energy transition across the residential sector that contributes to the majority of energy consumption. Fourth, suppose Nepal's commitments regarding the Paris Climate Agreement and the sustainable development goals will be delivered. In that case, the total DMC will drop by a fraction in CMS and by almost 10\% in SDGs with reference to the NEAS in 2050. This implies that the biomass and fossil fuels will likely achieve absolute decoupling from the economic growth in the SDGs, and a strong relative decoupling in the CMS and the LEAS. Finally, suppose Nepal is to sustain the progress made in the LDC graduation front. In that case, the total DMC will increase by almost fourfold and that the country will likely fail to deliver commitments regarding the Paris Climate Agreement and the SDGs. If we assume that LDC graduation is achieved while delivering the material consumption-related goals as committed by the government of Nepal under the Paris Climate Agreement and the SDGs, the goals do not seem to offset a part of a rise in material consumption in LDCGS.

\section{Unit test, cointegration, and causality analysis}

As an initial requirement to test for cointegration and subsequently the causality analysis, several unit tests were performed (e.g., ADF, PP, and ZA tests). We found that none of the variables' time series data is integrated of order two. Instead, they are of order zero and one $(I(0)$ and $I(1))$. This justifies the use of the ARDL bound test for cointegration. Table 3 shows the result of unit tests on the logarithmic transformation of variables. The ADF test showed that most variables are stationary at their first difference, barring urban and rural populations. The PP test showed that most variables are stationary at their level values. The ZA test concurred with the PP test by indicating that most variables are stationary at their level values, except the rural population. In addition, the ZA test identified structural breaks in the variables' time-series data and the year of structural break, as shown in Table 3.

Table 4 presents outputs from the ARDL bound test for cointegration. The computed values of $F$ statistics are compared with the critical values suggested by Narayan (2004) to determine if cointegration exists between variables. Narayan (2004) critical values are more relevant than Pesaran et al. (2001) because of the small sample size $(N=28)$. We tested for cointegration for four models (Eq. (1) to Eq. (4)) to find that the null hypothesis of no integration can be rejected for the $F F$ and the NMM consumption models as their $F$ statistics values are greater than the 5\% upper critical bound. The $F$ statistics values lie between upper and lower critical bounds at a 5\% significance level for the $B M S$ and $M O$ consumption models. However, the estimated coefficients from ARDL models (Table 5) show that the lagged error correction term $\left(E C T_{\mathrm{t}-1}\right)$ has negative values for all models and is statistically significant at $5 \%$ for all. The statistically significant negative value of the $E C T_{\mathrm{t}-1}$ indicates a cointegration relationship between variables under study (Baek 2015). The statistically significant negative value of the $E C T_{\mathrm{t}-1}$ at $5 \%$ level for the biomass and metal ore consumption models contradicts the result of the ADRL bound test. Thus, the cointegration relationship between variables for biomass and metal ore consumption models is inconclusive. In a situation like this, Bannerjee et al. (1998) suggest using error correction terms to establish cointegration evidence. Therefore, we give more weightage to the cointegration relationship as shown by the $E C T_{\mathrm{t}-1}$ and conduct a vector error correction-based Granger causality test to shed more light on the relationship. Based on the coefficient estimates of ARDL models, the following paragraph explains the relationship between material consumption and their dependent variables-more importantly, the GDPC, and external financial inflows, such as Rem and ODA.

We used logarithmic values of variables' data for ARDL models, meaning the coefficients' estimates shown by Table 5 are elasticities of material consumption with respect to their explanatory variables. For the $B M S$ consumption model, the short-run coefficient estimates of the GDPC and Rem are not significant even at the $10 \%$ level. However, their long-run coefficient estimates are significant at a 5\% level. The positive value of the GDPC's long-run coefficient estimate (0.253) implies that an increase in the $G D P C$ (i.e., income) will cause an increase in $B M S$ consumption. The negative value of the statistically significant 
Table 3 Augmented Dickey-Fuller (ADF), Phillips Perron (PP), and Zivot-Andrews (ZA) unit root tests

\begin{tabular}{|c|c|c|c|c|c|}
\hline \multirow[t]{3}{*}{ Variables } & \multirow{2}{*}{\multicolumn{2}{|c|}{$\frac{\text { Augmented Dickey-Fuller (ADF) } t \text { stat }}{\text { Level }}$}} & \multicolumn{2}{|c|}{ Phillips Perron (PP) $t$ stat } & \multirow{3}{*}{$\begin{array}{l}\text { Zivot-Andrews (ZA) } t \text { stat } \\
\text { Level } \\
\text { Trend }\end{array}$} \\
\hline & & & \multicolumn{2}{|l|}{ Level } & \\
\hline & Constant & Trend & Constant & Trend & \\
\hline $\log (G D P C)$ & 0.658 & -1.9762 & $0.622 * * *$ & $-1.6934 * * *$ & $-2.572 * * *(1998)$ \\
\hline $\log ($ Rem $)$ & -0.941 & -1.217 & $-0.657 * *$ & $-1.526^{* *}$ & $-3.151 * * *(2008)$ \\
\hline $\log (O D A)$ & 1.012 & -2.377 & $0.528 * * *$ & $-1.704 * * *$ & $-6.228 * * *(1999)$ \\
\hline $\log$ (Urbpop) & -0.796 & -2.826 & $9.508 * * *$ & 2.869 & $-6.843 * * *(2000)$ \\
\hline $\log$ (Rurpop) & -1.221 & $-3.498 *$ & $5.394 * * *$ & 1.146 & $-3.131(2005)$ \\
\hline $\log$ (ServicesShare) & -1.134 & -1.555 & $-0.737 * *$ & $-2.04 * *$ & $-4.054 * *(2005)$ \\
\hline $\log (B M S)$ & -0.875 & $-2.75^{* *}$ & $-0.466^{* * *}$ & $-3.343 * * *$ & $-3.658 * *(1999)$ \\
\hline $\log (F F)$ & -1.199 & -1.971 & $-1.67 * * *$ & $-2.68 * * *$ & $-2.754 * * *(2007)$ \\
\hline $\log (N M M)$ & -1.291 & -1.749 & $-1.252 * * *$ & $-1.488 * * *$ & $-2.782 *(2003)$ \\
\hline \multirow[t]{2}{*}{$\log (M O)$} & $-0.257^{*}$ & $-1.442 * *$ & $-1.046^{*}$ & $-2.458^{*}$ & $-6.281 * *(2009)$ \\
\hline & \multicolumn{2}{|l|}{ First difference } & \multicolumn{2}{|l|}{ First difference } & First difference \\
\hline$\Delta \log (G D P C)$ & $-2.747 * *$ & $-2.946^{*}$ & -4.035 & -4.173 & $-5.059(2007)$ \\
\hline$\Delta \log ($ Rem $)$ & $-2.943 * *$ & $-2.963 * *$ & -4.407 & -4.366 & $-6.222 * *(2001)$ \\
\hline$\Delta \log (O D A)$ & $-3.268 * * *$ & $-4.173 * * *$ & $-11.128 * *$ & $-10.783 * *$ & $-6.977 *(2006)$ \\
\hline$\Delta \log ($ Urbpop) & -1.729 & -0.456 & 1.000 & -0.475 & $-2.410(2011)$ \\
\hline$\Delta \log$ (Rurpop) & -1.221 & $-3.498^{*}$ & 0.673 & -1.857 & $-2.167(2013)$ \\
\hline$\Delta \log ($ ServicesShare $)$ & $-3.992 * * *$ & $-4.016^{* * *}$ & -5.675 & -5.616 & $-6.049(2000)$ \\
\hline$\Delta \log (B M S)$ & $-5.139 * * *$ & $-5.042 * * *$ & -7.523 & -7.48 & $-6.942(2005)$ \\
\hline$\Delta \log (F F)$ & $-2.749 * * *$ & $-2.659 * * *$ & -5.668 & 5.58 & $-5.95(2001)$ \\
\hline$\Delta \log (N M M)$ & $-2.466 * *$ & $-2.495 * *$ & -3.338 & -3.315 & $-3.885(2000)$ \\
\hline$\Delta \log (M O)$ & $-4.783 * * *$ & $-5.174 * * *$ & $-8.243 * *$ & $-8.874 * *$ & $-7.978 *(2012)$ \\
\hline
\end{tabular}

${ }^{* * *}$ Statistical significance at $1 \%$ levels, $* *$ statistical significance at $5 \%$ levels. * Statistical significance at $10 \%$ levels

$\Delta$ denotes the first difference term for the variables. The potential structural beak point position (year) is shown in the parenthesis for trend model by the Zivot-Andrews (ZA) unit root test. Lag lengths are selected based on the AIC Akaike information criterion

Table 4 ARDL bound test

\begin{tabular}{lclcl}
\hline Estimated models & $F$ statistics & $\begin{array}{l}I(0) \\
\text { 5\% Significance } \\
\end{array}$ & & \multicolumn{3}{l}{$\begin{array}{l}\text { level } \\
\text { leverion }\end{array}$} & \\
\cline { 3 - 4 } $\log (B M S)$ & 3.763 & 3.272 & 4.306 & Cointegration \\
\hline $\log (F F)$ & 21.57 & 3.272 & 4.306 & Cointegration \\
$\log (N M M)$ & 8.363 & 4.090 & 4.663 & Cointegration \\
$\log (M O)$ & 4.510 & 4.090 & 4.663 & Cointegration \\
\hline
\end{tabular}

long-run coefficient estimate of the Rem $(-0.025)$ means that any reduction in remittance inflow will unlikely drive $B M S$ consumption in the longer-term. The negative values of $O D A$ 's statistically significant short-run and long-run coefficient estimates show that any reduction in $O D A$ inflows will not reduce $B M S$ consumption in both the shorter and longer-term. This contradicts the findings from regularized ridge regression models (Table 2), where $O D A$ 's coefficient estimate is positive for $B M S$ consumption. Therefore, we explain this relationship based on results from the Granger causality test. The rural population has a strong bearing on
$B M S$ consumption as the high positive value of its long-run coefficient estimate (0.899) is statistically significant at a $5 \%$ level.

For the $F F$ consumption, a decrease in income (i.e., $G D P C$ ) will not affect how this material is consumed in the shorter-term. However, the statistically significant positive value of the long-run coefficient estimate of the GDPC (1.285) means that increase in income will increase $F F$ consumption in Nepal. The statistically significant low positive value of the short-run coefficient estimate of Rem (0.092) means that any reductions in remittance inflow will have a minimum effect on $F F$ consumption. This corresponds to the results from the regularized regression (the "Results from the ridge regression" section), where Rem has a low negative coefficient estimate for the $F F$ consumption. In the longerterm, reductions in remittance inflows may not cause reductions in FF consumption, as indicated by the statistically significant negative long-run coefficient estimate of the Rem $(-0.889)$. Contrastingly, reductions in $O D A$ inflows will not reduce fossil fuel consumption in the shorter-term. This corresponds to the findings from regularized ridge regression (Table 2), where $O D A$ has a very low coefficient estimate 


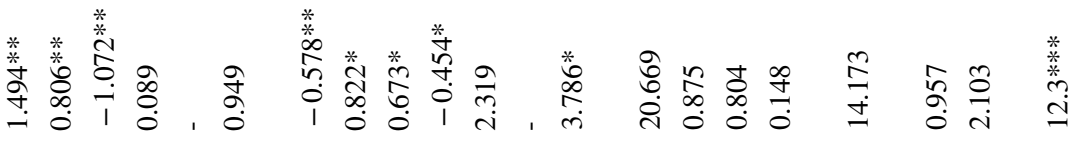

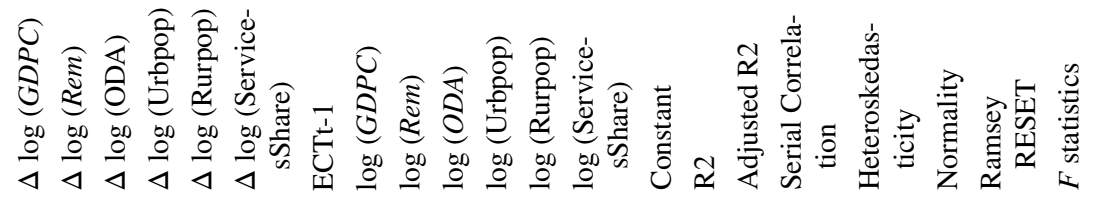

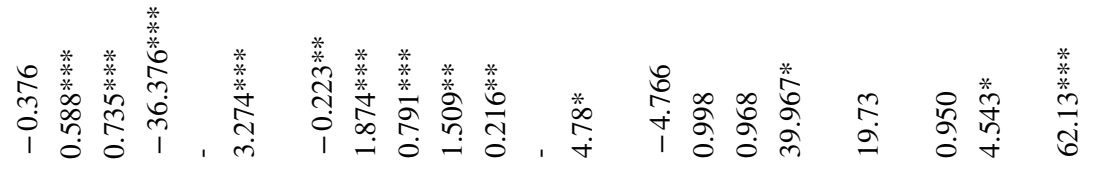

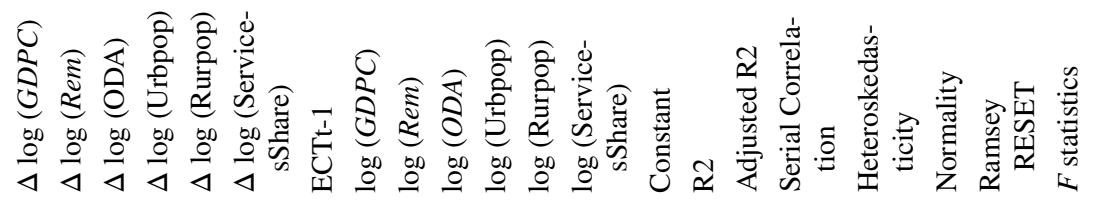

$\gtreqless$

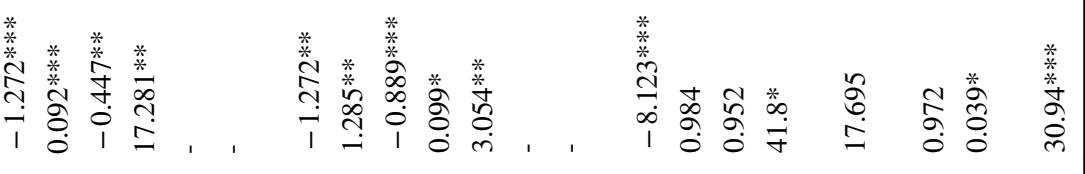

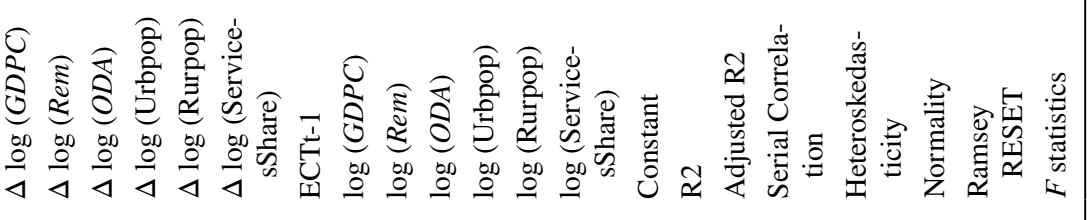

志

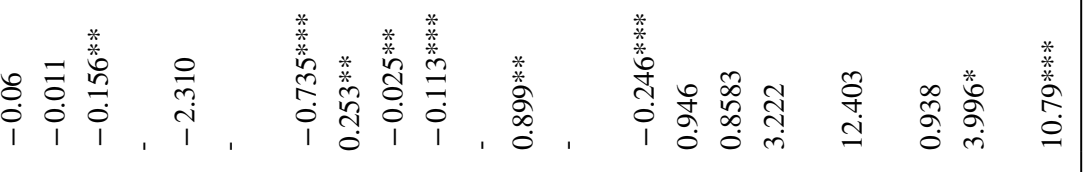

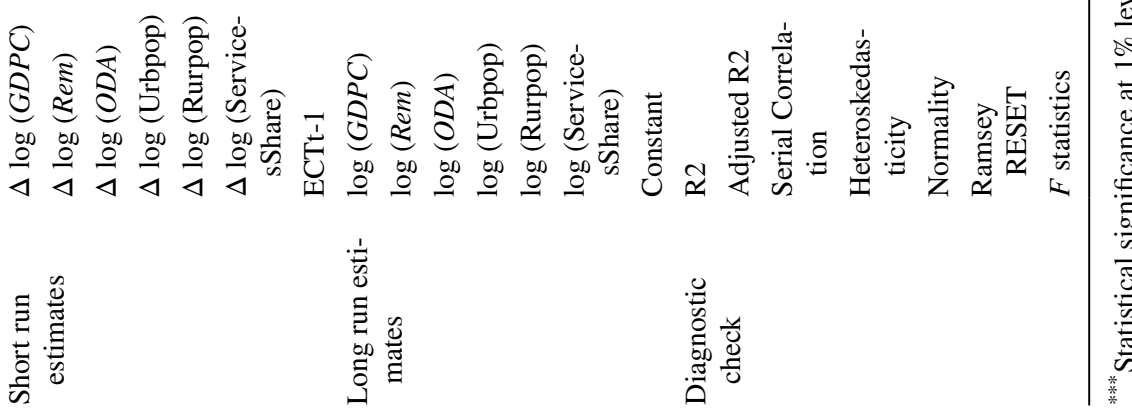


for $F F$ consumption. In the longer-term, the coefficient estimate of $O D A$ is not significant at the 5\% level. Intuitively, the growth in the urban population will drive the $F F$ consumption in both the shorter- and longer-term. Table 5 confirms this as the short- and long-run coefficient estimates of Urbpop have high positive values and are also statistically significant at the 5\% level. However, the long-term impact of growth in the urban population on $F F$ consumption will weaken significantly compared to the short-term impact as the coefficient estimate drops from 17.281 to 3.054. The growth in income $(G D P C)$ will partially compensate for the weakened impact of the Urbpop in the longer-term.

The GDPC has a negative short-run coefficient estimate, which is not statistically significant even at a $10 \%$ level for the NMM consumption (Table 5), which corresponds to the results of the regularized regression model for $N M M$ consumption (Table 2). However, the statistically significant positive long-run coefficient estimate of the GDPC implies that any increase in income will increase the $N M M$ consumption in the longer-term. The increase in remittance and $O D A$ inflows will also increase the consumption of the nonmetallic mineral in both shorter- and longer-term as indicated by their short-run and long-run coefficient estimates, which are positive and statistically significant at 5\% level. The short-run negative and positive long-run coefficient estimates of the urban population in the $N M M$ consumption ARDL model imply that the urban population has a longterm proportional relationship with the $N M M$ consumption, which is confirmed by the regularized ridge regression model (Table 2). Unlike the $N M M$ consumption, the $M O$ consumption depends highly on the income $(G D P C)$ in both shorter- and longer-term as the GDPC's short and long-run coefficient estimates are positive and statistically significant. Here, the remittance is also a cause for increased $M O$ consumption in both the short-run and long-run, as shown by its positive coefficient estimates, which are significant at $5 \%$ and $10 \%$, respectively. However, unlike remittance, any decrease in $O D A$ inflows is unlikely to cause reductions in $M O$ consumption in both the shorter- and longer-term. The income and remittance inflows will largely drive metal consumption as both short and long-run coefficient estimates of the urban population are not significant at the 5\% level. The ServicesShare has a positive long-run coefficient estimate but is statistically significant at only a $10 \%$ level.

We conducted the diagnostic check for four ARDL models to test serial correlation, normality of residuals, and heteroskedasticity. Results from these tests (Table 5) show that all four models are free from misspecification problem (Ramsey RESET test), have no serial correlation (Lagrange Multiplier tests) at 5\% significance level, have normally distributed residuals (Shapiro-Wilk test), and have homoscedastic residuals (Breusch-Pagan Test).
These results substantiate the validity of the ARDL models and the cointegration relationship among the variables. We also conduct the stability tests to check the stability of the ARDL models by using cumulative sum (CUSUM), and cumulative sum of squares (CUSUMQ) tests as proposed by Brown et al. (1975). These tests are important to understand the long-run parameter stability in cointegrating equations. The CUSUM and CUSUM of squares plots (Fig. 5) remain within the 5\% critical bound level, meaning that the models' parameters are consistent and stable.

Based on the evidence of a cointegration relationship between materials consumption and their explanatory variables, we conducted a Granger causality test to identify the direction of a causal relationship, which is not possible to exactly pinpoint by using cointegration tests. Tables 6 , 7,8 , and 9 present the results from the Granger causality test, which is based on the vector error correction mechanism (VECM). Table 6 shows a short-run unidirectional causal relationship running from $O D A$ to $B M S$ consumption, which corresponds to the findings from the ARDL model (Table 5). There is also a long-run unidirectional causal relationship running from the $O D A$ to the biomass consumption as the lagged correction term is statistically significant at the $10 \%$ level. However, unlike the results from the ARDL model, the VECM Granger causality test did not find the long-run causal relationship running from the GDPC and the Rem to the biomass consumption and vice versa. No evidence on causal relationship running from biomass consumption to the GDPC means that the increase in income and remittance rarely contributes to the $B M S$ consumption. There is also both short and longrun causal relationship running from the GDPC to $F F$ consumption and a short-run causal relationship running from $F F$ consumption to the GDPC. The short-run bidirectional causal relationship between the GDPC and fossil fuels indicates that $F F$ consumption increases income. No short- and long-run causal relationship between the Rem and $O D A$ with fossil fuel consumption contradicts the findings from the ARDL model. Both short- and long-run unidirectional causal relationships run from the Rem and $O D A$ to the $N M M$ consumption (Table 8), meaning these external financial inflows contribute to the $N M M$ consumption. There is also a short- and long-run bidirectional causal relationship between the GDPC and NMM consumption at a $10 \%$ significance level, which implies that the $N M M$ consumption contributes to the increase in income. This finding corresponds to the findings from the ARDL model (Table 5). Finally, both short- and long-run unidirectional causal relationship runs from the $G D P C$, Rem, and $O D A$ (Table 9) to $M O$ consumption, which indicates that these variables are significant in terms of increasing the consumption of metal ores. 

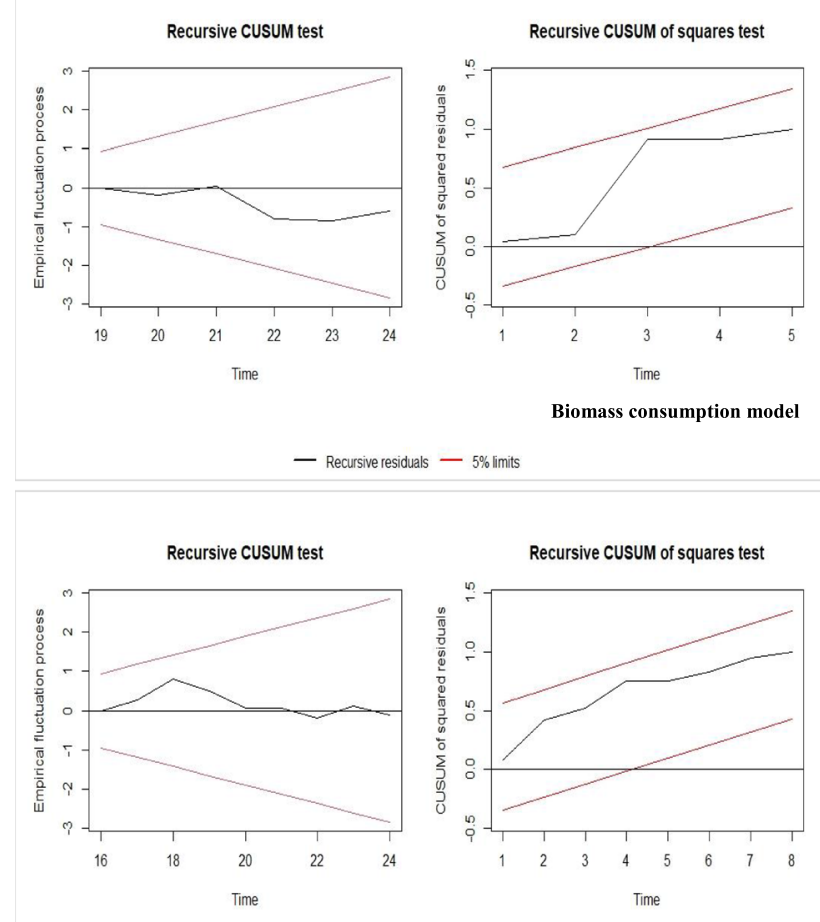

- Recursive residuals $-5 \%$ Imits
Recursive Cusum of squares test

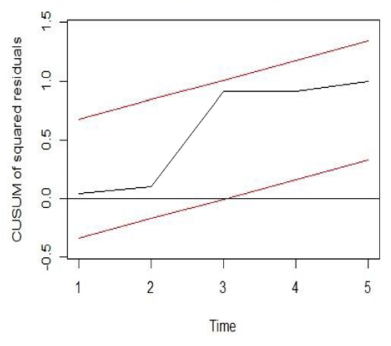

Biomass consumption mode

Recursive CUSUM of squares test

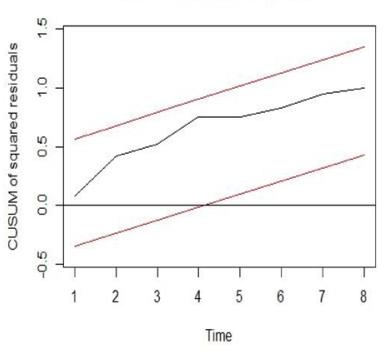

Non-metallic minerals

consumption model

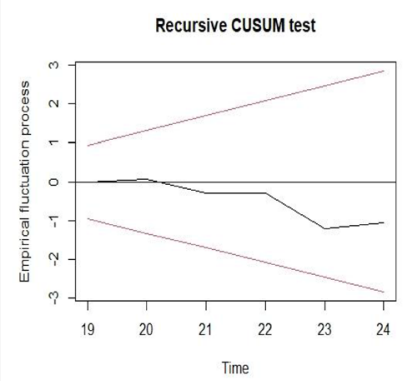

Time

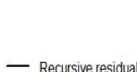

— Recursive residu

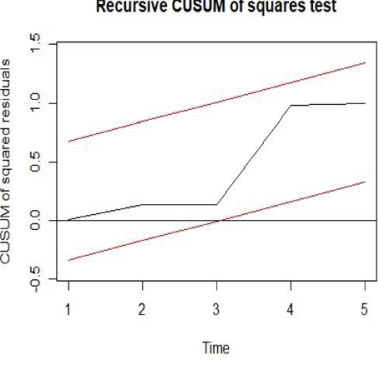

Fossil fuels consumption model
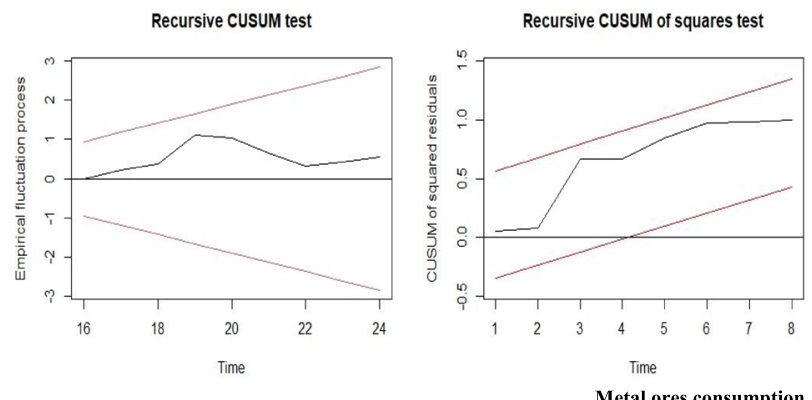

- Recursive residuals $-5 \%$ limits

Fig. 5 CUSUM and CUSUM of squares stability test plots for four material consumption models. The continuous line (red) represents critical bounds at $5 \%$ significance level

Table 6 Granger causality analysis for biomass consumption

Dependent variable $\quad$ Short run analysis $(F$ statistics $)$

Long run analysis ( $t$ statistics)

\begin{tabular}{lllllcc} 
& $\Delta \log (B M S)$ & $\Delta \log (G D P C)$ & $\Delta \log ($ Rem $)$ & $\Delta \log ($ ODA $)$ & $\Delta \log ($ Rurpop) & ECTt-1 \\
\hline$\Delta \log (B M S)$ & & -0.611 & 0.315 & $-0.789^{*}$ & 1.982 & $-1.883^{*}$ \\
$\Delta \log (G D P C)$ & -2.550 & & -0.828 & 0.850 & -37.558 & 2.789 \\
$\Delta \log ($ Rem $)$ & -4.187 & 3.727 & & $4.0395^{*}$ & 8.471 & 19.590 \\
$\Delta \log ($ ODA $)$ & 0.438 & 0.470 & -1.008 & & 52.752 & 1.988 \\
$\Delta \log$ (Rurpop) & -0.378 & 1.308 & $-0.692^{*}$ & 0.007 & 2.765 \\
\hline
\end{tabular}

Table 7 Granger causality analysis for fossil fuels consumption

Dependent variable Short run analysis ( $F$ statistics)

Long run analysis ( $t$ statistics)

\begin{tabular}{|c|c|c|c|c|c|c|}
\hline & & \multirow{2}{*}{$\begin{array}{l}\text { statistics) } \\
\text { ECTt-1 }\end{array}$} \\
\hline & $\Delta \log (F F)$ & $\Delta \log (G D P C)$ & $\Delta \log ($ Rem $)$ & $\Delta \log (O D A)$ & $\Delta \log ($ Urbpop) & \\
\hline$\Delta \log (F F)$ & & $-2.8361 * *$ & 0.576 & 0.3623 & 22.094 & $-2.341 *$ \\
\hline$\Delta \log (G D P C)$ & $0.577 *$ & & 0.516 & -1.177 & 23.0103 & -1.455 \\
\hline$\Delta \log ($ Rem $)$ & -1.136 & 3.9177 & & 0.8756 & -39.605 & 3.346 \\
\hline$\Delta \log (O D A)$ & 0.420 & -0.638 & 0.441 & & -10.246 & -2.549 \\
\hline$\Delta \log ($ Urbpop) & 1.147 & -1.642 & 1.2125 & -1.6355 & & -1.047 \\
\hline
\end{tabular}


Table 8 Granger causality analysis for non-metallic minerals consumption

\begin{tabular}{|c|c|c|c|c|c|c|c|}
\hline \multirow[t]{2}{*}{ Dependent variable } & \multicolumn{5}{|c|}{ Short run analysis ( $F$ statistics) } & \multirow[b]{2}{*}{$\Delta \log ($ ServicesShare) } & \multirow{2}{*}{$\begin{array}{l}\text { Long run } \\
\text { analysis ( } t \\
\text { statistics) } \\
\text { ECTt-1 }\end{array}$} \\
\hline & $\Delta \log (N M M)$ & $\Delta \log (G D P C)$ & $\Delta \log ($ Rem $)$ & $\Delta \log (O D A)$ & $\Delta \log ($ Urbpop) & & \\
\hline$\Delta \log (N M M)$ & & $-4.9276^{* *}$ & $-2.128 * *$ & $-2.4659 * *$ & $-67.576^{*}$ & $-2.607 *$ & $-6.428 * *$ \\
\hline$\Delta \log (G D P C)$ & $0.432^{*}$ & & -0.609 & -0.2244 & -32.435 & -1.404 & $1.551^{*}$ \\
\hline$\Delta \log ($ Rem $)$ & 1.764 & 1.935 & & -1.1995 & 14.935 & -0.747 & -2.410 \\
\hline$\Delta \log (O D A)$ & -1.732 & 2.238 & -1.110 & & -55.045 & 0.899 & -1.732 \\
\hline$\Delta \log ($ Urbpop) & -1.023 & -1224 & 1.009 & 1.013 & & 1.013 & 1.003 \\
\hline$\Delta \log ($ ServicesShare $)$ & 0.379 & 0.392 & -0.455 & -0.503 & -21.849 & & -1.356 \\
\hline
\end{tabular}

Table 9 Granger causality analysis for metal ores consumption

\begin{tabular}{|c|c|c|c|c|c|c|c|}
\hline \multirow[t]{2}{*}{ Dependent variable } & \multicolumn{5}{|c|}{ Short run analysis ( $F$ statistics $)$} & \multirow[b]{2}{*}{$\begin{array}{l}\Delta \log (\text { Ser- } \\
\text { vicesShare })\end{array}$} & \multirow{2}{*}{$\begin{array}{l}\text { Long run } \\
\text { analysis ( } t \\
\text { statistics) } \\
\text { ECTt-1 }\end{array}$} \\
\hline & $\Delta \log (M O)$ & $\Delta \log (G D P C)$ & $\Delta \log ($ Rem $)$ & $\Delta \log (O D A)$ & $\Delta \log ($ Urbpop) & & \\
\hline$\Delta \log (M O)$ & & $4.313^{* *}$ & $-1.438 * *$ & $-1.573^{*}$ & $-42.149 * *$ & $3.371^{*}$ & $-2.272 * * *$ \\
\hline$\Delta \log (G D P C)$ & 1.121 & & -1.335 & -1.295 & -6.136 & -1.200 & -0.563 \\
\hline$\Delta \log ($ Rem $)$ & 1.252 & 1.077 & & -1.123 & 32.581 & 7.408 & -1.475 \\
\hline$\Delta \log (O D A)$ & -0.340 & 1.823 & -0.507 & & -57.194 & 0.512 & 0.843 \\
\hline$\Delta \log ($ Urbpop$)$ & -1.155 & -1.042 & -1.024 & 1.014 & & 1.746 & 1.199 \\
\hline$\Delta \log ($ ServicesShare $)$ & 0.831 & -0.610 & -0.494 & -0.443 & -26.431 & & -1.064 \\
\hline
\end{tabular}

${ }^{* * *}$ Statistical significance at $1 \%$ levels, $* *$ statistical significance at $5 \%$ levels, *statistical significance at $10 \%$ levels

\section{Impulse response analysis}

We conducted impulse response analysis to understand the impact of shocks on the explanatory variables to response variables (Fig. 6). A shock in the GDPC will initially increase biomass consumption (Fig. 6(A)), which then decreases and a similar process repeats. The consumption of fossil fuels will follow a similar pattern to biomass consumption but with a higher frequency of fluctuation (Fig. 6(D) ). The non-metallic mineral consumption will also follow a similar pattern to that of biomass and fossil fuel consumption. However, the fluctuation is less severe, and any increase or decrease will persist for a relatively long time (Fig. 6(G) ). The consumption of metal ores will decrease initially for some time but will recover dramatically and continue to increase over time (Fig. 6(J)).

A shock in remittance will unlikely change the biomass consumption significantly initially (Fig. 6(B) ). However, following a period of almost no impact initially, there will be a sharp reduction in biomass consumption, which will recover swiftly. Fossil fuels' consumption will increase initially for some time, which will decrease briefly to recover and continue increasing consumption (Fig. 6(E) ). Nonmetallic minerals will see an initial increase, remaining stable for a more extended period (Fig. 6(H) ). Metal ore consumption will unlikely change because of the shock in the remittance (Fig. 6(K) ).

A shock in the $O D A$ will increase biomass consumption for an extended period, which will decrease briefly to recover and continue to grow in biomass consumption (Fig. 6(C) ). Fossil fuels will decrease immediately but will recover and increase sharply for some time. Then, there will be a sharp decline and increase quickly, remaining almost stable (Fig. 6(F) ). Nonmetallic minerals' consumption will decrease immediately, and the decline persists for some time to see frequent fluctuations (Fig. 6(I) ). Metal ore consumption will also decrease immediately but will recover slowly, and in the longer-term, it will continue to increase (Fig. 6(L)).

\section{Forecast error variance decomposition}

We conducted the forecast error variance decomposition to decompose the variance of the forecast errors from exogenous shocks and to understand the shocks' impact on the short-run dynamics of the system. Figure 7 shows the forecast error variance decomposition (FEVD) bar 

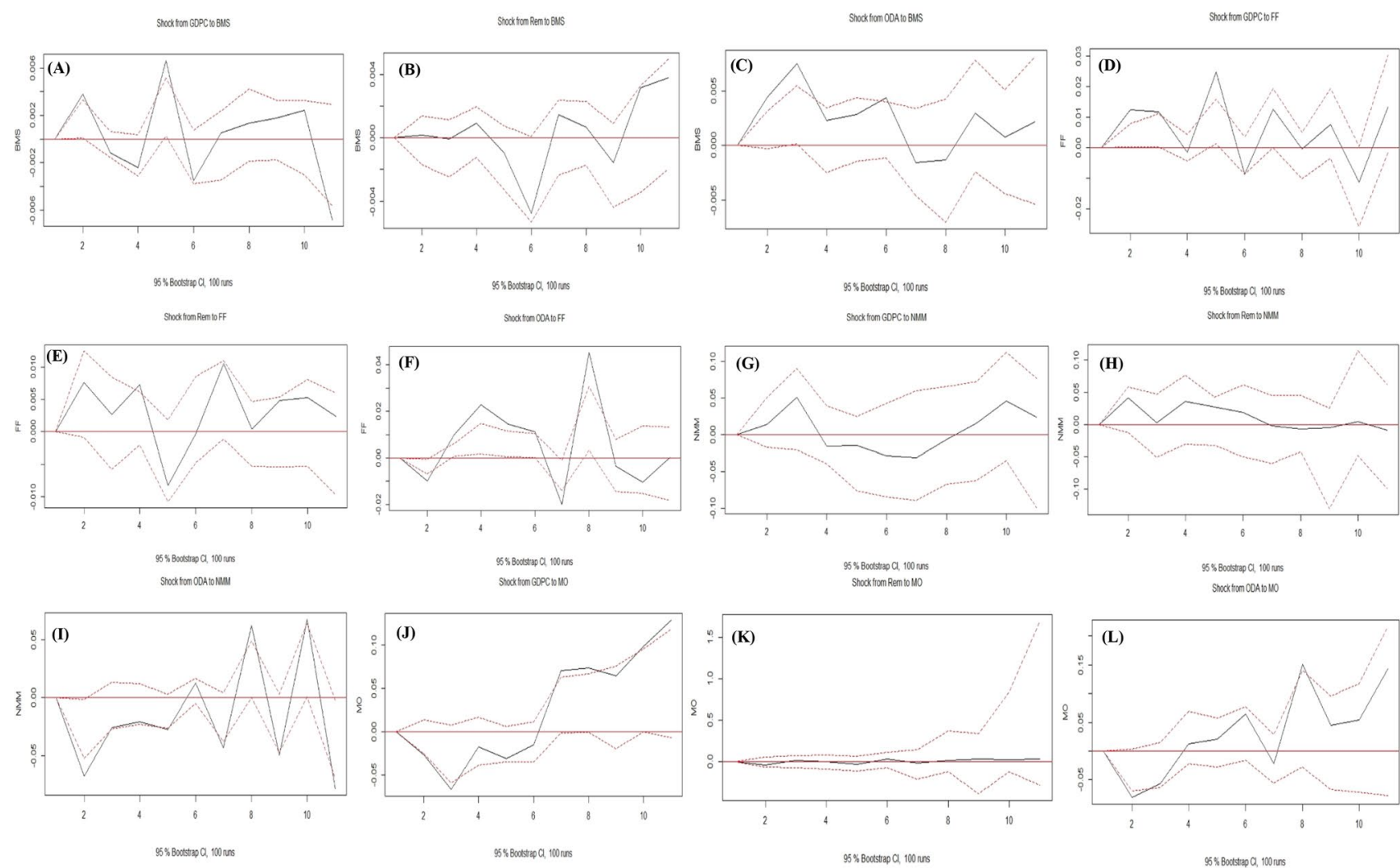

Fig. 6 Impulse response analysis

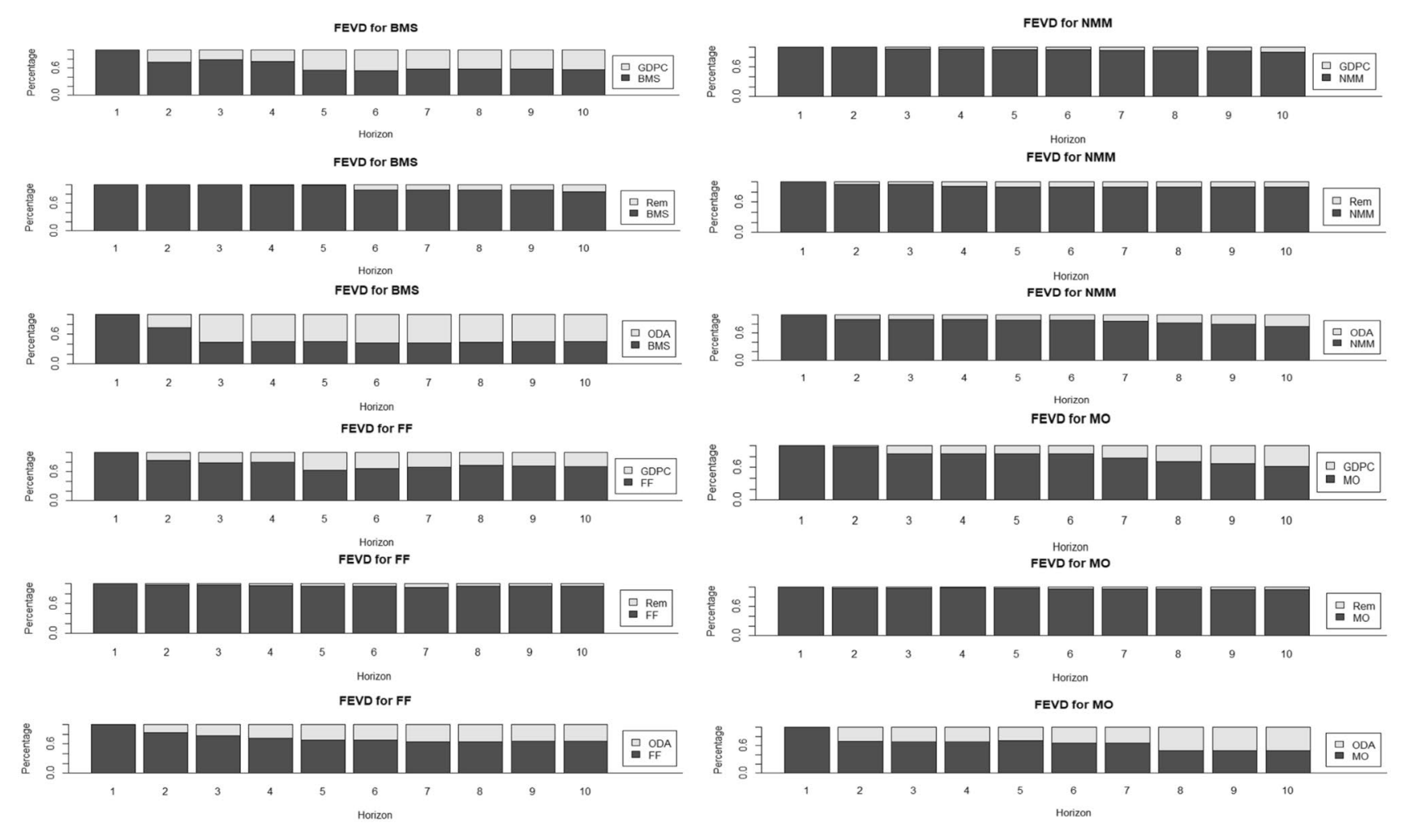

Fig. 7 Forecast error variance decomposition 
graphs for each material type and the forecasting horizon for ten years. The level of variation experienced by the $B M S$ consumption results mainly from the $O D A$ followed by the $G D P C$. While the system becomes stable after the third year from the $O D A$ 's shock to the $B M S$, the system becomes stable from the GDPC's shock after the fifth year. The contribution of the remittance is marginal in the ten years, and the system becomes stable from the sixth year. The variation experienced by the $F F$ consumption results mainly from the $O D A$ (stable after the fourth year) and the GDPC (stable after the fifth year). Like the $B M S$ consumption, the variance contribution of the remittance is marginal for the $F F$ consumption, and the system becomes stable after the fifth year. The $O D A$ is the main variable responsible for the variation in the $N M M$ and $M O$ consumption. While the GDPC follows the $O D A$, remittance contribution in the $N M M$ and $M O$ consumption variation is marginal. Unlike the $B M S$ and the $F F$ consumption, the variation in the $N M M$ and $M O$ does not appear to be stable for a longer time. The variation because of their own shocks is prominent across four materials.

\section{Discussion and conclusion}

This research generated three key insights into DMC in Nepal, which could apply to other LDCs. First, non-metallic minerals, together with biomass, will dominate the total DMC in the future, and the share of fossil fuels will be nominal in Nepal. Therefore, even in future (in 2050), with a much higher level of income relative to 2020, the composition of different material types in DMC will not be proportional as in most developed and developing countries. Second, the LDC graduation pathway that seems attractive for LDCs' policymakers has relatively higher DMC intensity. As a result, the country may not deliver commitments regarding the Paris Climate Agreement and the SDGs. Third, the external financial inflows such as the remittance and $O D A$ have a strong bearing on material consumption in Nepal, and there is both short- and long-run unidirectional causality running from external financial inflows to the consumption of nonmetallic minerals and metal ores. Biomass and fossil fuel consumption appeared to be less dependent on remittance, but both short- and long-run causal relationships run from the $O D A$ to biomass consumption. We discuss the three key insights in the following paragraphs.

The developed countries from the Asia-Pacific region, Australia, Japan, and South Korea have a higher proportion of non-metallic minerals, fossil fuels, and metal ores. Each of these contributes more than the biomass in their total DMC (WU Vienna 2020). The emerging Asia-Pacific countries, such as India, China, Malaysia, Thailand, and Vietnam, have a higher share of non-metallic minerals and biomass and a small proportion of the metal ores. The non-metallic minerals-based DMC with a lower share of fossil fuels is a common trait for middle-income countries (Wu et al. 2019). This research found that Nepal's material composition in the DMC will resemble the material composition of the emerging Asia-Pacific countries in 2050. Thus, the building-up of stock (e.g., infrastructures) that emerged post-2000 would continue to rise rapidly in Nepal, particularly after the mid2030s (Fig. 4). The net imports of materials (e.g., metal ores, non-metallic minerals, and fossil fuels) will also increase to meet the growing materials demand, meaning an improved integration into the global material trade. The LDCs have a weak integration into the global economy because of their low physical trade flows (Schaffartzik and Pichler 2017) and low urbanization rates (Wu et al. 2019). While the nonmetallic materials and metal-based DMC indicate an industrial economy (Sarkodie 2020), our findings show that the sudden structural change in the economy from agro-based to service sector-based will enable the industrial economy in the future.

Another important aspect of the notable change in the structure of DMC is the potential reductions in the nation's material intensity. ${ }^{3}$ Most LDCs have high material intensity because of the higher proportion of biomass in their DMC. For example, the Asian LDCs, Bangladesh (2.45 kg/USD), Cambodia (4.66 kg/USD), Laos (6.76 kg/USD), Myanmar (2.81 kg/USD), and Nepal (5.27 kg/USD) have material intensity values that are above Asia-Pacific region's average of $2.04 \mathrm{~kg} / \mathrm{USD}$ (UNESCAP, 2021a, b). While the exportoriented manufacturing sector of Bangladesh and Myanmar reduced their material intensity despite their higher share of biomass in the DMC (Fig. 2), Nepal and Laos have the weakest manufacturing sector to generate the GDP (World Bank 2021). The higher proportion of the non-metallic minerals in the DMC in the future, and lower share of biomass, which are indicators of being an industrial economy (Steinberger et al. 2010; Sarkodie 2020), implies that Nepal's material intensity will reduce even amidst a weak productive sector of an economy (manufacturing). However, there is a caveat-further expansion of the service sector. This finding contradicts the understandings about technological change being the only way forward to reduce the material intensity of LDCs as the progress in material intensity from structural changes in an economy is tailing off in LDCs, such as for Bangladesh and Nepal (Baniya et al. 2021a). We infer that leveraging the productive use of growing non-metallic material consumption in LDCs can reduce material intensity even with minimum technological intervention, particularly

\footnotetext{
${ }_{3}$ Material intensity measures the unit DMC to generate a unit GDP.
} 
in the residential energy sector, to reduce biomass consumption and the total DMC. The energy demand (e.g. biomass) in the residential sector is one of the significant contributors to the DMC in the Asia-Pacific LDCs, including Nepal (World Bank 2021).

Considering the looming LDC graduation in 2026 (UNCDP 2021), the recent economic downturn from the COVID-19 (UNCTAD 2020), and the poverty implication of the Paris Climate Agreement in LDCs (Campagnolo and Davide 2019), the policymakers in Nepal and other LDCs face a dilemma. They ponder whether to focus on economic growth or sustainable development objectives, including SDGs 7,12 , and 13 . The LDC graduation scenario presents itself as a suitable DMC pathway in the future for its potential to resolve poverty and resource accessibility issues prevalent in many LDCs, including Nepal. However, it is material-intensive and unsustainable on Nepal's part in delivering the Paris Climate Agreement and the SDGs. Thus, the understanding of sustainable growth as a growth pathway that helps LDCs achieve LDC graduation by 2030 (SDSN 2014) appears to be confusing. Nonetheless, reflecting on research scholars' viewpoint about wealthy nations potentially giving up some of their material consumption for LDCs' future growth (Duro et al. 2018; O'Neill et al. 2018; Schandl et al. 2018; Giljum et al. 2014), it is natural to give more weightage to the economic growth and social outcomes in the LDCs, including Nepal. However, the important question is as follows: Can equitable allocation of material use help LDCs achieve their social outcomes?

In the current state, equitable allocation of material use may not help LDCs achieve their social outcomes because of the weak correlation between GDP growth and biomass consumption (Steinberger et al. 2010; Wu et al. 2019). Biomass is a dominant material type for most Asian LDCs, including Nepal. Nepal's biomass consumption is largely subsistence-based and is used within the residential sector instead of productive manufacturing and service sectors. We used GDPC instead of the GDP as an explanatory variable in the regularized regression model (Table 2) and the ARDL model (Table 5), which showed that GDPC's coefficient is significant for biomass consumption. However, it does not Granger cause biomass consumption (Table 6). The GDPC accounts for the population, which is strongly correlated with the biomass consumption in LDCs (Steinberger et al. 2010). In the future, a higher share of non-metallic minerals that are strongly correlated with both population and GDP (Steinberger et al. 2010) means a better chance to achieve social outcomes (e.g., poverty reduction) from the equitable allocation of materials. This is confirmed by our findings from the non-metallic minerals' ARDL model that has a high long-run GDPC's coefficient estimate (Table 5), and there is also both short and long-run bidirectional causal relationship between the GDPC and the consumption of the non-metallic mineral.
We found that the external financial inflows, such as the remittance and $O D A$, impact the material consumption in Nepal, especially the non-metallic minerals and the metal ores, in both the short and long run (Table 8 and Table 9). Thus, these external financial inflows will be critical in the future when non-metallic minerals and metal ores will form much of Nepal's DMC. While the shock in the remittance will cause minor disturbance in the material consumption, shock in the $O D A$ and $G D P C$ will cause notable disturbances in the material consumption (Fig. 6 and Fig. 7). The coefficient estimates of both remittance and $O D A$ are stronger in their $N M M$ and $M O$ consumption ARDL models (Table 5). However, only ODA's coefficient estimates are found to be statistically significant for the biomass consumption, and also, Granger causes biomass consumption. Thus, reflecting on the seemingly dormant role of the remittance, a significant contributor to Nepal's GDP, in the biomass consumption, and the negative elasticity of fossil fuel consumption from remittance in the ARDL model indicates the role it can play in the clean energy transition. Remittance is found to have a direct causality relationship with renewable energy consumption (Das et al. 2021). Therefore, as a policy insight, we suggest that the remittance, which is a source of income for $24 \%$ of households in Nepal (Takenaka et al. 2020), can be utilized for upscaling of the modern renewable energy technologies, share of which is below world's average in most LDCs, including Nepal. This will help replace a fraction of biomass that has a weak correlation with the GDP. For other Asian LDCs, the share of the remittance-receiving households is 14\% for Bangladesh, 9\% for Cambodia, $16 \%$ for Lao PDR, and 18\% for Myanmar. We suggest that the policy focused on transforming consumption-based remittance into potential sources of investments for energy transition can help deliver energy and material consumption-related commitments of the Paris Climate Agreement and the SDGs for Nepal and other Asian LDCs.

The small-scale household and community level modern renewable energy technologies (e.g. solar PV, biogas, and micro-hydro electricity) are less susceptible to external shocks to an economy (Baniya and Giurco 2021). Therefore, considering the contribution of biomass in the total DMC in future (Fig. 4) and the role of remittance in household consumption, policies targeting the dissemination of the small-scale modern renewable energy technologies in the rural areas can help reduce the DMC in the long run. We suggest this policy measure keeping in mind the increasing demand of non-metallic materials as the rate of urbanization grows and given Nepal's weak material use efficiency, which will likely increase as the energy sector transition from being biomass-based to being based on small-scale modern renewable energy technologies. This policy measure will also contribute to achieving SDGs 7, 12, and 13 as the 
rural population will have access to clean energy, reduce the DMC, and be climate mitigation-oriented.

Finally, this research limits its focus to the material consumption in LDCs, with Nepal as a case country, and the DMC reduction narrative is largely biomass-based for its contribution to the total DMC. Therefore, while we propose policies focusing on disseminating the small-scale household and community level modern renewable energy technologies, we limit the discussion to reduce non-metallic material consumption despite it appearing to be a significant contributor to the future DMC. A higher proportion of the non-metallic material in the total DMC is common for developing and developed countries. Therefore, LDCs can afford to increase their non-metallic material consumption solely because they need to achieve their socio-economic objectives. Therefore, future research can emphasize the non-metallic consumption strategies in the LDCs as they are challenged with achieving both environmental and socio-economic objectives. As of now, to our knowledge, academic research papers have not addressed how LDCs such as Nepal can achieve environmental and socio-economic objectives simultaneously, particularly in the context of LDC graduation. Thus, we recommend the aforementioned as the future research area.

Supplementary Information The online version contains supplementary material available at https://doi.org/10.1007/s11356-021-18050-9.

Author contribution Bishal Baniya conceptualized the research idea, collected and analyzed the data, designed the methodological framework, wrote the original draft, and edited the final manuscript. Prem Prakash Aryal conceptualized the research idea, collected and analyzed the data, designed the methodological framework, and wrote the original draft.

Funding This research is funded by the Australian Government Research Training Program Scholarship.

Data availability The data and analysis are available from the authors upon request.

\section{Declarations}

Ethical approval Not applicable.

Consent to participate Not applicable.

Consent to publish Not applicable.

Competing interests The authors declare no competing interests.

\section{References}

Ahmad M, Jabeen G, Shah SAA et al (2021) Assessing long- and shortrun dynamic interplay among balance of trade, aggregate economic output, real exchange rate, and $\mathrm{CO} 2$ emissions in Pakistan. Environ Dev Sustain. https://doi.org/10.1007/s10668-021-01747-9
Alfredsson E, Bengtsson M, Brown HS, Isenhour C, Lorek S, Stevis, DVergragt P (2018) Why achieving the Paris Agreement requires reduced overall consumption and production, Sustainability: Science. Practice and Policy 14(1):1-5. https://doi.org/10.1080/ 15487733.2018.1458815

Alola AA, Akadiri S, Usman O (2021) Domestic material consumption and greenhouse gas emissions in the EU-28 countries: implications for environmental sustainability targets. Sustain Dev 29(2):388-397. https://doi.org/10.1002/sd.2154

Baek J (2015) Environmental Kuznets curve for CO2 emissions: the case of Arctic countries. Energy Economics 50:13-17. https://doi. org/10.1016/j.eneco.2015.04.010

Baniya B and Giurco D (2021) Resource-efficient and renewable energy transition in the five least developed countries of Asia: a post-COVID-19 assessment, Sustainability: Science, Practice, and Policy. https://doi.org/10.1080/15487733.2021.2002025

Baniya B, Giurco D Kelly S (2021a) Green growth in Nepal and Bangladesh: empirical analysis and future prospects. Energy Policy, 149. https://doi.org/10.1016/j.enpol.2020.112049

Baniya B, Giurco D, PrakashP KS (2021b) Mainstreaming climate change mitigation actions in Nepal : influencing factors and processes. Environ Sci Policy 124:206-216. https://doi.org/10.1016/j.envsci.2021.06.018

Baniya B, Giurco D, Kelly S (2021c) Changing policy paradigms: how are the climate change mitigation-oriented policies evolving in Nepal and Bangladesh? Environ Sci Policy 124:423-432. https:// doi.org/10.1016/j.envsci.2021.06.025

Bannerjee A, Dolado, Mestre R (1998) Error-correction mechanism tests for cointegration in single equation framework. Journal of Time Series Analysis, Vol. 19:267-283. Retrieved from http://earchivo2.uc3m.es/jspui/bitstream/10016/3275/2/error-correction JTSA-1998-ps.pdf

Baynes T M, Musango J K (2018) Estimating current and future global urban domestic material consumption. Environ Res Lett. 13(6). https://doi.org/10.1088/1748-9326/aac391

Bharadwaj B, Pullar D, Seng To L, Leary J (2021) Why firewood? Exploring the co-benefits, socio-ecological interactions and indigenous knowledge surrounding cooking practice in rural Nepal. Energy Res Soc Sci 75(January):101932. https://doi.org/10. 1016/j.erss.2021.101932

Brown R, Durbin J, Evans J (1975) Techniques for testing the constancy of regression relationships over time. J R Stat Soc. Series B (Methodological), 37(2), 149-192. Retrieved July 30, 2021, from http://www.jstor.org/stable/2984889

Campagnolo L, Davide M (2019) Can the Paris deal boost SDGs achievement? An assessment of climate mitigation co-benefits or side-effects on poverty and inequality. World Dev 122:96-109. https://doi.org/10.1016/j.worlddev.2019.05.015

Chishti MZ, Ahmad M, Rehman A, Khan, MK (2021) Mitigations pathways towards sustainable development: assessing the influence of fiscal and monetary policies on carbon emissions in BRICS economies. J Clean Prod, 292. https://doi.org/10.1016/j. jclepro.2021.126035

Combes JL, Ebeke C (2011) Remittances and household consumption instability in developing countries. World Dev 39(7):1076-1089. https://doi.org/10.1016/j.worlddev.2010.10.006

Dahal MP (2018) Stride of service sector in Nepal's trajectories of structural change. Econ J Dev Issues 21(1-2):69-98. https://doi. org/10.3126/ejdi.v21i1-2.19024

Das A, Mcfarlane A, Carels L (2021) Empirical exploration of remittances and renewable energy consumption in Bangladesh. Asia-Pacific J Reg Sci 5(1):65-89. https://doi.org/10.1007/ s41685-020-00180-6

Demirhan H (2020) dLagM: An R package for distributed lag models and ARDL bounds testing. PLoS ONE 15(2):e0228812. https:// doi.org/10.1371/journal.pone.0228812 
Dhakal S, Oli SK (2020) The impact of remittance on consumption and investment: a case of province five of Nepal. Quest J Manag Soc Sci 2(1):27-40. https://doi.org/10.3126/qjmss.v2i1.29018

Dickey D, Fuller W (1979) Distribution of the estimators for autoregressive time series with a unit root. J Am Stat Assoc 74(366):427-431. https://doi.org/10.2307/2286348

Dickey D, Fuller W (1981) Likelihood ratio statistics for autoregressive time series with a unit root. Econometrica 49(4):1057-1072. https://doi.org/10.2307/1912517

Dong L, Dai M, Liang H, Zhang N, Mancheri N, Ren et al (2017) Material flows and resource productivity in China, South Korea and Japan from 1970 to 2008: a transitional perspective. J Clean Prod 141:1164-1177. https://doi.org/10.1016/j.jclepro.2016.09.189

Duro JA, Schaffartzik A, Krausmann F (2018) Metabolic inequality and its impact on efficient contraction and convergence of international material resource use. Ecol Econ 145:430-440. https:// doi.org/10.1016/j.ecolecon.2017.11.029

Ehrlich P, Holdren J (1971) Impact of population growth. Science, 171(3977), 1212-1217. Retrieved July 9, 2021, from http://www. jstor.org/stable/1731166

Friedman J, Hastie T, Tibshirani R (2010) "Regularisation paths for zgeneralized linear models via coordinate descent." Journal of Statistical Software, 33(1), 1-22. https://www.jstatsoft.org/v33/ i01/

Gareth J, Witten D, Hastie T, Tibshirani R (2014) An introduction to statistical learning: with applications in R. Springer Publishing Company, Incorporated. 2014.

Giljum S, Dittrich M, Lieber M, Lutter S (2014) Global patterns of material flows and their socioeconomic and environmental implications: a MFA study on all Countries world-wide from 1980 to 2009. Resources 3(1):319-339. https://doi.org/10.3390/resou rces3010319

Government of Nepal (GoN) (2020) Second Nationally Determined Contributions, Government of Nepal, Kathmandu. https://www4. unfccc.int/sites/ndcstaging/PublishedDocuments/Nepal\%20Sec ond/Second $\% 20$ Nationally $\% 20$ Determined $\% 20$ Contribution $\%$ 20(NDC)\%20-\%202020.pdf

Granger C (1969) Investigating causal relations by econometric models and cross-spectral methods. Econometrica 37(3):424-438. https:// doi.org/10.2307/1912791

Haberl H, Wiedenhofer D, Virág D, Kalt G et al (2020) A systematic review of the evidence on decoupling of GDP, resource use and GHG emissions, part II: Synthesizing the insights. Environ Res Lett. 15(6). https://doi.org/10.1088/1748-9326/ab842a

Haider MZ, Hossain T, Siddiqui OI (2016) Impact of remittance on consumption and savings behavior in rural areas of Bangladesh. J Bus 1(4):25. https://doi.org/10.18533/job.v1i4.49

Hamilton (1994) Time Series Analysis, Princeton University Press. Princeton (1994).

Hoerl AE, Kennard RW (1970) Ridge regression: biased estimation for nonorthogonal problems. Technometrics 2:109-120

Hubacek K, Baiocchi G, Feng K et al (2017) (2017) Poverty eradication in a carbon constrained world. Nature Communication 8:912. https://doi.org/10.1038/s41467-017-00919-4

Hussain I, Rehman A (2021) Exploring the dynamic interaction of CO2 emission on population growth, foreign investment, and renewable energy by employing ARDL bounds testing approach. Environ Sci Pollut Res 28(2021):39387-39397. https://doi.org/10.1007/ s11356-021-13502-8

IEA (2021) International Energy Agency - Energy Balance Database (2018). https://www.iea.org/sankey/\#?c=World\&s=Balance

Johansen S (1991) Estimation and hypothesis testing of cointegration vectors in Gaussian vector autoregressive models. Econometrica 59(6):1551-1580. https://doi.org/10.2307/2938278

Kafle S, Parajuli R, Adhikari K, Kwang SHE, Oh C et al (2018) Forest-based biomass supply potential and economics for the pellet production in Nepal. Int J Green Energy 15(1):1-7. https://doi. org/10.1080/15435075.2016.1171228

Kahlert J, Gribsholt SB, Gammelager H, Dekkers OM (2017) Luta G (2017) Control of confounding in the analysis phase - an overview for clinicians. Clin Epidemiol 9:195-204. https://doi.org/10.2147/ CLEP.S129886

Khan K, Babar SF, Oryani B et al (2021) (2021) Role of financial development, environmental-related technologies, research and development, energy intensity, natural resource depletion, and temperature in sustainable environment in Canada. Environ Sci Pollut Res. https://doi.org/10.1007/s11356-021-15421-0

Krausmann F, Gingrich S, Eisenmenger N, Erb KH et al (2009) Growth in global materials use, GDP and population during the 20th century. Ecol Econ 68(10):2696-2705. https://doi.org/10.1016/j.ecole con.2009.05.007

Kuhn M (2008) Building predictive models in R using the caret package. J Stat Softw 28(5):1-26

Murshed M (2020) Are trade liberalization policies aligned with renewable energy transition in low and middle income countries? An Instrumental Variable approach. Renew Energy 151:1110-1123. https://doi.org/10.1016/j.renene.2019.11.106

Murshed M, Rahman MA, Alam MS et al (2021) (2021) The nexus between environmental regulations, economic growth, and environmental sustainability: linking environmental patents to ecological footprint reduction in South Asia. Environ Sci Pollut Res 28:49967-49988. https://doi.org/10.1007/s11356-021-13381-z

Murshed M, Tanha MM (2021) Oil price shocks and renewable energy transition: empirical evidence from net oil-importing South Asian economies. Energ Ecol Environ 6:183-203. https://doi.org/10. 1007/s40974-020-00168-0

Narayan PK (2004) The saving and investment nexus for China: evidence from cointegration tests. Appl Econ 37, 2005(17):19791990. https://doi.org/10.1080/00036840500278103

National Planning Commission (NPC) (2020) National Review of Sustainable Development Goals, Government of Nepal, Kathmandu. https://sustainabledevelopment.un.org/content/documents/26541 VNR_2020_Nepal_Report.pdf

OECD (2021) OECD.Stat (flows by providers and recipient data query), https://stats.oecd.org/Index.aspx?datasetcode=TABLE2A

O’Neill DW, Fanning AL, Lamb WF, Steinberger JK (2018) A good life for all within planetary boundaries. Nature Sustainability 1(2):88-95. https://doi.org/10.1038/s41893-018-0021-4

Parajuli R, Østergaard PA, Dalgaard T, Pokharel GR (2014) Energy consumption projection of Nepal: an econometric approach. Renew Energy 63:432-444. https://doi.org/10.1016/j.renene. 2013.09.048

Pesaran MH, Shin Y, Smith RJ (2001) Bounds testing approaches to the analysis of level relationships. J Appl Economet 16:289-326. https://doi.org/10.1002/jae.616

Peterson BG, Carl P, Boudt K, Bennett R, Ulrich J and Zivot E et al. (2015) Package Performance Analytics, Available at: http:// www.r-forge.r-project.org/projects/returnanalytics

Pfaff B (2016) Package 'urca'. Unit root and cointegration tests for time series data, 2016 http://cran.r-project.org/web/packages/urca/urca.pdf

Phillips PCB, Perron P (1988) Testing for a unit root in time series regression. Biometrika 75:335-346

Popescu GH, Andrei JV, Nica E, Mieilă M, Panait M (2019) Analysis on the impact of investments, energy use and domestic material consumption in changing the Romanian economic paradigm. Technol Econ Dev Econ 25(1):59-81. https://doi.org/10.3846/ tede.2019.7454

R Core Team (2017) R: A language and environment for statistical computing. R Foundation for Statistical Computing, Vienna, Austria. URL http://www.R-project.org/.

Rehman A, Ma H Ozturk I (2021a). Do industrialization, energy importations, and economic progress influence carbon emission in 
Pakistan. Environ Sci Pollut Res 28, 45840-45852 (2021). https:// doi.org/10.1007/s11356-021-13916-4

Rehman A, Ma H, Radulescu M, Sinisi CI, Yousaf Z (2021b) Energy crisis in Pakistan and economic progress: decoupling the impact of coal energy consumption in power and brick kilns. Mathematics 9(17):2083. https://doi.org/10.3390/math9172083

Rehman A, Radulescu M, Ma H, Dagar V, Hussain I, Khan MK. (2021c). The impact of globalization, energy use, and trade on ecological footprint in Pakistan: does environmental sustainability exist? Energies. 2021; 14(17):5234. https://doi.org/10.3390/ en 14175234

Rehman A, Ma H, Ozturk I et al. (2021d). The dynamic impacts of CO2 emissions from different sources on Pakistan's economic progress: a roadmap to sustainable development. Environ Dev Sustain (2021). https://doi.org/10.1007/s10668-021-01418-9

Rehman A, Ma H, Ahmad M, Irfan M, Traore O, Chandio AA (2021e) Towards environmental sustainability: devolving the influence of carbon dioxide emission to population growth, climate change, Forestry, livestock and crops production in Pakistan. Ecological Indicators, 125. https://doi.org/10.1016/j.ecolind.2021.107460

Sarkodie SA (2020) Causal effect of environmental factors, economic indicators and domestic material consumption using frequency domain causality test. Science of the Total Environment, 736. https://doi.org/10.1016/j.scitotenv.2020.139602

Schaffartzik A, Pichler M (2017) Extractive economies in material and political terms: Broadening the analytical scope. Sustainability (Switzerland), 9(7). https://doi.org/10.3390/su9071047

Schandl H, Eisenmenger N (2006) Regional patterns in global resource extraction. J Ind Ecol 10(4):133-147. https://doi.org/10.1162/jiec. 2006.10.4.133

Schandl H, Fischer-Kowalski M, West J, Giljum S, Dittrich M et al (2018) Global material flows and resource productivity forty years of evidence. J Ind Ecol 22(4):827-838. https://doi.org/10.1111/ jiec. 12626

SDSN (2014) An Action Agenda for Sustainable Development (Sustainable Development Solutions Network, 2014).

Steckel JC, Brecha RJ, Jakob M, Strefler J, Luderer G (2013) Development without energy? Assessing future scenarios of energy consumption in developing countries. Ecol Econ 90:53-67. https:// doi.org/10.1016/j.ecolecon.2013.02.006

Steinberger JK, Krausmann F, Eisenmenger N (2010) Global patterns of materials use: a socio-economic and geophysical analysis. Ecol Econ 69(5):1148-1158. https://doi.org/10.1016/j.ecolecon.2009. 12.009

Takenaka A,, Villafuerte J, Gaspar R, Narayanan B (2020) COVID19 Impact on international migration, remittances, and recipient households in developing Asia1 Aiko. Adb Briefs, 0(148). https:// www.adb.org/sites/default/files/publication/622796/covid-19impact-migration-remittances-asia.pdf

Tibshirani R (1996) Regression shrinkage and selection via the lasso. Journal of the Royal Statistical Society. Series B
(Methodological), 58(1), 267-288. Retrieved July 30, 2021, from http://www.jstor.org/stable/2346178

UNCDP (2021) Report on the twenty-third session (22-26 February 2021), Economic and Social Council, Official Records, 2021, Supplement No. 13, New York, USA

UNCTAD (2011) National Services Policy Review for Nepal, Geneva, Switzerland, https://unctad.org/system/files/official-document/ ditctncd20103_en.pdf

UNCTAD (2020) The Least Developed Countries Report 2020: THE LEAST DEVELOPED COUNTRIES REPORT 2020 Productive capacities for the new decade. New York and Geneva: United Nations Conference on Trade and Development (UNCTAD). https://unctad.org/en/pages/PublicationWebflyer.aspx?publicatio nid $=2571$

UNESCAP (2021) Resource Efficiency Simulation, https://sdghe lpdesk.unescap.org/re/index.html

UNESCAP (2021) United Nations Economic and Social Commission for Asia and the Pacific: Resource Efficiency Simulation, https:// sdghelpdesk.unescap.org/re/nepal.html

Wagle UR (2012) Socio-economic implications of the increasing foreign remittance to Nepal: Evidence from the Nepal living standard survey. Int Migr 50(4):186-207. https://doi.org/10.1111/j.14682435.2011.00727.x

Watari T, Nansai K, Nakajima K (2021) Contraction and convergence of in-use metal stocks to meet climate goals. Glob Environ Chang 69:102284. https://doi.org/10.1016/j.gloenvcha.2021.102284

Weimin Z, Chishti MZ, Rehman A et al (2021) (2021) A pathway toward future sustainability: assessing the influence of innovation shocks on $\mathrm{CO} 2$ emissions in developing economies. Environ Dev Sustain. https://doi.org/10.1007/s10668-021-01634-3

Weisz H, Krausmann F, Amann C, Eisenmenger N, Erb KH, Hubacek K, Fischer-Kowalski M (2006) The physical economy of the European Union: Cross-country comparison and determinants of material consumption. Ecol Econ 58(4):676-698. https://doi.org/ 10.1016/j.ecolecon.2005.08.016

World Bank (2021) World Bank Open Data. https://data.worldbank.org/

WU Vienna (2020) Comparing countries/regions by different indicators. zVisualization based upon the UN IRP Global Material Flows Database. Vienna University of Economics and Business. Online available at: materialflows.net/visualisation-centre.

Wu Z, Schaffartzik A, Shao Q, Wang D, Li G, Su Y, Rao L (2019) Does economic recession reduce material use? Empirical evidence based on 157 economies worldwide. J Clean Prod 214:823-836. https://doi.org/10.1016/j.jclepro.2019.01.015

Zivot E, Andrews DWK (2002) Further evidence on the great crash, the oil price shock, and the unit-root hypothesis. Journal of Business and Economic Statistics 20(1):25-44

Valensisi G (2020) COVID-19 and global poverty: are LDCs being left behind? The European Journal of Development Research 32(5):1535-1557. https://doi.org/10.1057/s41287-020-00314-8

Publisher's note Springer Nature remains neutral with regard to jurisdictional claims in published maps and institutional affiliations. 